\title{
Impactos de medidas "antidumping" adotadas pelos EUA sobre o setor siderúrgico de Minas Gerais e o restante do Brasil
}

\author{
Palavras-chave \\ antidumping, fluxo de \\ comércio, setor siderúrgico, \\ insumo-produto.
}

Classificação JEL F10, F13.

\section{Key words}

antidumping, trade flow, steel industry, input-output

JEL Classification F10, F13.

\section{Resumo}

Analisar o impacto de medidas antidumping aplicadas pelos Estados Unidos sobre exportaçôes do setor siderúrgico de Minas Gerais, para o período entre 1999 e 2002, foi o objetivo deste trabalho. Os resultados mostraram que tal medida teve efeitos estatisticamente significativos sobre a redução no fluxo de comércio. $\mathrm{Na}$ análise da integração dos resultados econométricos com a abordagem de matrizes inter-regionais de insumo-produto, foi possível concluir que o setor mais afetado, no que se refere à produção, seria a siderurgia mineira, em que o impacto representou mais de 75\% do total, no período em análise. Com relaçáo ao emprego, o impacto sobre a siderurgia de Minas Gerais corresponde, em média, a mais de $50 \%$ do total de vagas que seriam criadas, caso nenhuma medida antidumping tivesse sido adotada; e a siderurgia do restante do país seria responsável por mais de $16 \%$ dos postos de trabalho criados no período.
Vinícius de Azevedo Couto Firme Professor ECO/FE/UFJF

Claudio R. F. Vasconcelos Professor do Mestrado em Economia Aplicada CMEA/FE/UFJF

\section{Abstract}

The aim of this paper was to analyze the effect of the United States antidumping policy over exports by the steelmaking industry of Minas Gerais between 1999 and 2002. The results showed antidumping to be an instrument which had a significant effect on the decrease in trade flows. After the analyses of the integration between econometrics results and the inter-regional input-product matrices, it was possible to conclude that the most affected sector was steelmaking, with $75 \%$ of the total product effects in the period. With regards to employment, the average impact on the Minas Gerais steelmaking industry was more than 50\% of the total new job opportunities, if neither antidumping measure had been adopted; and the steelmaking industry of the other regions of the country would be responsible for more than 16\% of job opportunities created in the period. 


\section{1_Introdução}

A partir da década de 1970, o mecanismo antidumping $^{1}$ se tornou um importante instrumento de proteção comercial em razão das reduçôes tarifárias nas diversas rodadas do Acordo Geral de Tarifas e Comércio/Organização Mundial de Comércio (GATT/OMC). Segundo Vasconcelos e Vasconcelos (2005), esse crescimento ocorreu tanto nos países usuários tradicionais como nos Estados Unidos, no Canadá, na Austrália, na Nova Zelândia e nos países da Comunidade Europeia quanto nos países sem tradição no uso de tais medidas como México, Brasil, Argentina e África do Sul. ${ }^{2}$

Tal expansão tem levado os estudiosos do comércio internacional a mudar o foco de análise de instrumentos convencionais de política de proteção comercial para a análise dos efeitos de medidas antidumping (Staiger; Wolak, 1994; Prusa, 1996, 1999; Koning; Vandenbussche; Springael, 1999; Zanardi, 2004).

Miranda (2003) argumenta que o grande volume de investigaçóes antidumping registrado nos anos 80 e 90 foi um retrocesso no processo de liberalização comercial. Embora esse número de investigações ainda não atinja parcela significativa do volume comercializado internacionalmente, tais procedimentos geram incerteza e efeitos negativos sobre o comércio internacional.

Com relação à economia brasileira, observa-se que as medidas antidumping ${ }^{3}$ correspondem a mais de $70 \%$ do total de investigaçóes abertas contra

A prática de discriminaçáo
internacional de preços,
através da fixaçáo de preços
de exportaçóes abaixo
dos preços dos produtos
similares destinados ao
mercado interno pela
firma exportadora, é
comumente definida como
dumping. Assim, com
o intuito de reduzir ou
eliminar o prejuízo causado
às indústrias domésticas
do país importador, a
medida antidumping seria
o mecanismo de correçáo de condutas que distorçam o comércio internacional ao serem impostas tarifas adicionais sobre as importaçóes advindas de firmas que estariam praticando o dumping. Para obter uma taxonomia de dumping, ver Willig (1998).
2 Araújo Jr. et al. (2001,
p.7), ao analisar os países
da Área de Livre Comérci da Área de Livre Comérci também verificaram uma

\author{
elevação na utilização deste \\ tipo de medida. Além disso, \\ os autores revelaram que \\ muitas vezes as medidas \\ antidumping são utilizadas \\ como ferramentas de proteção, \\ onde o verdadeiro propósito \\ é desviar o foco da falta de \\ competitividade interna para \\ o comercio desleal externo. \\ Nas palavras dos autores: \\ "Developed countries, and a \\ growing number of developing \\ ones, have increasingly \\ relied on antidumping laws
}

to provide import relief to particular economic sectors. Part of the (political) appeal of antidumping lies in the way it shifts the focus of attention from the shortcomings of the domestic industry to the 'unfair' trade practices of foreign firms."

3 Considerando todas as ferramentas de defesa comercial: medidas antidumping, compensatórias e salvaguardas. 
4 Neste caso, a alteração do preço interno seria tanto maior quanto menor a participaçáo do país importador no mercado internacional do produto em questão. Sob a hipótese de país pequeno, a imposição de tarifa a importação seria totalmente refletida nos preços internos.

5 Desagregados em 13 setores para cada região. as exportaçóes brasileiras no período de 1989 a 2006. Especificamente, para o caso de produtos laminados a quente da siderurgia nacional, constata-se que a aplicação de direitos antidumping e medidas de salvaguarda utilizadas pelo governo dos EUA resultaram em tarifas proibitivas às exportaçóes no ano de 2000. Para evitar a imposição desses direitos, foram assinados acordos de quotas e preços mínimos, os quais, porém, não conduziram a melhoras no cenário de exportação desses produtos. $\mathrm{O}$ acordo de preços foi encerrado em fevereiro de 2002, e o acordo de quotas, em setembro de 2004 (Patriota, 2007).

Nesse sentido, segundo Blonigen e Prusa (2001, p. 3), o mecanismo antidumping "é simplesmente uma moderna forma de protecionismo". Conforme os modelos teóricos de comércio, a imposição de tarifas aos produtos importados acarretaria em redução da demanda de importaçóes com aumento da produção e preços do produto em questão no país importador. ${ }^{4}$ Portanto, um resultado econômico esperado da prática antidumping seria justamente a redução do volume de importaçóes.

Assim, a aplicação de medidas antidumping por parte dos EUA, no ano de 2000, contra os produtos de aço laminados a quente exportados pelo Bra- sil e consequentemente de Minas, pode ter gerado impacto negativo sobre a produção e emprego, tanto no próprio setor quanto nos demais setores produtivos do Estado e do país. Pois, além de o setor siderúrgico, em média, ter sido responsável por aproximadamente $8 \%$ do total exportado pelo país e quase $25 \%$ do total exportado pelo Estado de Minas Gerais, no acumulado entre 1994 e 2006 (Brasil/MDIC/ALICEweb, 2008), segundo Firme (2009), o setor siderúrgico de Minas Gerais apresentaria elevado índice de ligaçôes para trás. Em outras palavras, quando a siderurgia mineira cresce, ela impulsiona a produção dos demais setores do Estado, uma vez que passa a demandar mais desses. Já a siderurgia do restante do Brasil mostrou características de setor-chave no período de 1996 a 2003.

Nesse contexto, objetiva-se analisar os possíveis efeitos das principais medidas antidumping (AD) adotadas pelos EUA sobre as exportaçóes do Estado de Minas Gerais referentes ao setor siderúrgico, no período de 1999 a 2002. Especificamente, o objetivo é quantificar os impactos dessas medidas restritivas sobre as exportaçóes da economia mineira, em termos de produção e emprego no setor siderúrgico e demais setores ${ }^{5}$ de Minas Gerais e no restante do Brasil. Para tanto, será utilizada a matriz inter-regional 
de insumo-produto ${ }^{6}$ com dados referentes a esse período.

Cabe ressaltar o caráter inovador deste trabalho dado que, até o momento, não foi encontrada na literatura consultada outra pesquisa que tentasse verificar o impacto de medidas restritivas ao comércio exterior via integração de modelo econométrico com análise de insumoproduto. Além disso, a importância da abordagem de insumo-produto está no fato de ela captar os efeitos diretos e indiretos da variação de demanda final de cada setor.

O restante do artigo está estruturado da seguinte forma: a seção 2 expóe a evolução da aplicação do mecanismo antidumping contra as exportaçóes brasileiras. $\mathrm{Na}$ seção 3, foram analisados trabalhos empíricos de mensuração de medidas restritivas sobre o fluxo de comércio. $\mathrm{Na}$ seção 4, foi realizada uma breve referência às vantagens e limitaçôes da integração do modelo econométrico com as matrizes de insumo-produto. Em seguida, desenvolveu-se o método de mensuração de impactos sobre as exportaçóes do setor siderúrgico e como esses afetam o produto e o emprego setorial. No final dessa seção, encontra-se a base de dados utilizada. Na seçấo 5, consta a análise dos resultados obtidos. Por fim, na seção 6, está a conclusão do trabalho.

\section{2_Produtos siderúrgicos brasileiros alvos de medidas "antidumping" adotadas pelos EUA}

Com relação às medidas de proteção adotadas contra as exportaçóes do setor siderúrgico brasileiro, entre 1989 e 2006, constata-se que existem 25 medidas aplicadas ou em andamento contra a siderurgia nacional, sendo essas divididas entre cinco países: EUA, com 16 medidas (12 antidumping e quatro de subsídios); Argentina e México, com três medidas de antidumping cada um; Canadá e Turquia, com respectivamente duas e uma medidas antidumping (Brasil/MDIC/ Decom, 2008).

Para o total exportado pela siderurgia, brasileira e mineira, entre 1994 e 2006, observa-se que, entre os países que adotaram medidas de proteção contra $\mathrm{o}$ setor siderúrgico, destacam-se os EUA, como destino de, aproximadamente, 29\% e $24 \%$ de todo o montante exportado pelo país e por Minas Gerais, respectivamente, nesse período. Seguido pela Argentina, com $7 \%$ pelo Brasil e $6 \%$ por Minas Gerais; México, com 4\% e 3\%, na mesma ordem; Canadá com $3 \%$ por ambos; e Turquia com apenas $1 \%$ pelo Brasil e nenhum por Minas Gerais. Em vista disso, conclui-se que os Estados Unidos são o país que mais recebe produtos siderúrgicos provenientes

\footnotetext{
Para mais detalhes, consultar o tópico referente à base de dados.
} 
Tabela 1_Exportação acumulada de produtos siderúrgicos brasileiros e mineiros, entre 1996 e 2006, discriminação por capítulos do sistema harmonizado (valores em US\$ milhões FOB)

\begin{tabular}{|c|c|c|c|}
\hline & Brasil & Minas Gerais & $\begin{array}{l}\text { Participação de Minas Gerais } \\
\text { nas exportações do Brasil (\%) }\end{array}$ \\
\hline Exportaçóes totais & 18.085 & 6.299 & 35 \\
\hline Capítulo 72 & 16.214 & 6.027 & 37 \\
\hline Participação 72 (\%) & 90 & 96 & - \\
\hline Capítulo 73 & 1.871 & 272 & 15 \\
\hline Participação 73 (\%) & 10 & 4 & - \\
\hline
\end{tabular}

Fonte: Elaboraçấo própria com base no Brasil/MDIC/ALICEweb (2008).

Mais detalhes sobre desvio de comércio, em Staiger e Wolak (1994). do Brasil (de Minas Gerais) e ao mesmo tempo o que mais os penaliza (Brasil/MDIC/Decom, 2008).

Portanto, utilizando o princípio da parcimônia e considerando a boa representatividade apresentada pelos EUA, optou-se por trabalhar apenas com as medidas antidumping requeridas por esse país em detrimento dos demais. Neste estudo, o enfoque foi apenas sobre os impactos diretos gerados por medidas antidumping, adotadas pelos Estados Unidos sobre as exportaçóes de Minas Gerais, provenientes do setor siderúrgico, quando esse é citado, desconsiderando a possibilidade de desvio de comércio quando ele não é mencionado. ${ }^{7}$

Pode-se notar, de acordo com a Tabela 1, que as exportaçóes da siderurgia de Minas Gerais para os EUA, acumu- ladas entre 1996 e 2006, representaram aproximadamente $35 \%$ do montante total do país para esse setor. Grande parte desse total é proveniente do capítulo 72 (ferro fundido, ferro e aço) do sistema harmonizado, que representa $90 \%$ do total exportado pelo setor siderúrgico brasileiro e $96 \%$ do total exportado por Minas Gerais. O capítulo 73 (obras de ferro fundido, ferro e aço) representa $10 \%$ do total no Brasil e 4\% em Minas Gerais.

Apesar de o setor siderúrgico brasileiro ser um dos mais afetados por medidas antidumping, nem todos os produtos derivados do aço produzidos no Brasil são alvo de tais medidas. No relatório do Decom, disponível em Brasil/ MDIC/Decom (2008), pode-se perceber que apenas dez cestas de produtos foram alvo de medidas antidumping. Conside- 
rando o total exportado pela siderurgia nacional para os EUA, entre 1996 e 2006, pode-se concluir que os produtos siderúrgicos nacionais alvo de medidas antidumping adotadas pelos EUA não chegam a representar $8 \%$ do total exportado pelo Brasil para este país (Brasil/MDIC/ ALICEweb, 2008).

Analisando pela ótica de Minas Gerais, também não se nota grande diferença. $\mathrm{O}$ total de produtos exportados que foram alvo de medidas adotadas pelos EUA corresponde a pouco mais de $11 \%$ do montante que o referido Estado exportou para este país. A magnitude desses valores percentuais, porém, não deve afetar o escopo deste trabalho, visto que o objetivo central consiste em verificar se as medidas antidumping podem, de fato, alterar o fluxo comercial. Em se confirmando tal hipótese, buscou-se verificar como isso afetaria a produção e o emprego dos demais setores em MG e no restante do Brasil. Logo, mesmo que o impacto da medida seja relativamente pequeno, pode-se fazer inferência sobre o que poderá ocorrer caso mais medidas sejam adotadas sobre as exportaçóes desse setor.

Observando a Tabela 2, pode-se perceber que os produtos de aço laminados a quente representam a maioria do que foi exportado pelo Brasil com des- tino ao EUA. Considerando que as exportaçóes dessa cesta de produtos correspondem a pouco mais de US\$ 1 bilhão e 48 milhóes, e o total de produtos alvo é de, aproximadamente, US\$ 1,364 bilhão, pode-se constatar que os laminados a quente correspondem a quase $77 \%$ do montante exportado.

Além de ter significativa representatividade entre os demais produtos, os laminados a quente estão dentro da pauta de exportação de Minas Gerais, sendo essa unidade da Federação responsável por aproximadamente $46 \%$ do total exportado desse produto para os EUA (Tabela 2).

Desta forma, essa cesta de mercadorias foi incorporada no presente trabalho para analisar os efeitos das medidas antidumping adotadas pelos EUA sobre as exportaçóes do Estado de Minas Gerais que têm como destino aquele país. ${ }^{8}$ Para tanto, torna-se indispensável a análise de outros trabalhos empíricos com objetivos semelhantes aos propostos aqui, que possam auxiliar na confecção de um método de mensuração consistente e confiável, que é feito na seção seguinte.

\section{3_ Principais resultados de trabalhos empíricos}

Em dois trabalhos de Prusa (1996 e 1999), foram feitas estimativas visando captar
8 A abertura de processo antidumping pelos EUA, sobre produtos de aço laminados a quente (PALQ) exportados pelo Brasil, ocorreu em 22/10/1998. Em 19/2/1999, foi adotada uma medida provisória inibindo as exportações nacionais desse produto. Cabe ressaltar que, nas mesmas datas, foi aberto um processo antissubsídio (22/10/1998) e adotada uma medida provisória sobre os PALQs provenientes do Brasil (19/2/1999). Logo, como será visto adiante, o modelo econométrico proposto vai captar o efeito dessas duas medidas. Mais detalhes sobre as medidas adotadas, em Brasil/MDIC/Decom (2008). 
Tabela 2_Exportações brasileiras e participação mineira de produtos siderúrgicos alvo de medidas "antidumping" adotadas pelos EUA, para este país, entre 1996 e 2006 (valores em US\$ milhões FOB)

\begin{tabular}{|c|c|c|}
\hline Produto & Brasil & $\begin{array}{l}\text { Participação de Minas Gerais } \\
\text { nas exportações de produtos alvo (\%) }\end{array}$ \\
\hline & Capítulo 72 & \\
\hline Fio máquina aço inoxidável & 0.01 & 29 \\
\hline Barras de aço inoxidável & 17.19 & 0 \\
\hline Produtos de aço laminados a quente & 1048.50 & 46 \\
\hline Fio máquina carbono e de certas ligas de aço & 1.35 & 0 \\
\hline \multirow[t]{2}{*}{ TOTAL } & 1067.05 & 45 \\
\hline & Capítulo 73 & \\
\hline $\begin{array}{l}\text { Tubos p/ condução de fluídos de ligas de aço e carbono, } \\
\text { sem costura, seção circular e diâmetro reduzido }\end{array}$ & 24.71 & 91 \\
\hline Chapas grossas de aço alto carbono & 4.06 & 5 \\
\hline Certos cabos de aço para concreto armado & 87.31 & 60 \\
\hline Tubos ou conexóes sem liga, de solda circular & 30.80 & 93 \\
\hline Peças fundidas para construção & 48.24 & 87 \\
\hline Conexóes para tubos de solda de extremidade de ferro fundido & 102.20 & 96 \\
\hline TOTAL & 297.33 & 82 \\
\hline Total siderurgia $(72+73)$ & 1364.37 & 53 \\
\hline
\end{tabular}

Fonte: Elaboraçăo própria com base em Brasil/MDIC/Decom (2008) e Brasil/MDIC/ALICEweb (2008). 
os efeitos sobre os fluxos comerciais da economia norte-americana advindos de açóes antidumping abertas pelo governo deste país. Prusa (1999) verificou a evolução das importaçôes dos produtos citados quando a investigação é encerrada com a aplicação de algum tipo de medida; quando ela é simplesmente retirada pela firma peticionaria; e quando a investigação é encerrada sem aplicação de medidas. A amostra reúne os casos abertos pelo governo norte-americano entre 1980 e 1994. Em resumo, as estimativas de Prusa (1999) mostram que há queda nas importaçóes mesmo quando não são aplicadas medidas ou quando a petição é retirada, e que, tal como o estudo anterior já havia indicado, o desvio de comércio permanece significativo.

Por sua vez, Taylor (2004) analisa se há indícios de colusão na investigação de dumping para a economia dos EUA para os processos iniciados de 1990 a 1997, que terminaram com a retirada das petiçóes sem um acordo. A principal hipótese testada foi a de que o término de uma petição de investigação de dumping conduz a um aumento do preço el ou diminuição na quantidade das importações objeto de inquérito. Por meio de um sistema de equaçóes simultâneas de oferta e demanda por importaçóes, via método de Mínimos Quadrados em Três
Estágios (MQ3E), ${ }^{9}$ o autor utiliza em sua análise uma versão mais refinada do trabalho realizado por Prusa (1996) e semelhante a Prusa (1999).

Essa técnica de estimação corrige a correlação existente nos termos de erro e ajuda a atenuar um possível viés de variáveis omitidas. Variáveis binárias mensais foram incluídas em todas as equaçóes para captar os impactos sazonais. Os resultados desse trabalho, para os casos que foram retirados sem acordo, indicam que acordos colusivos não são comuns, pelo menos não na década de 1990 . Na maioria dos casos, ocorreu aumento ou não ocorreu nenhuma mudança no valor do comércio. Somente em dois dos 16 casos, os preços aumentaram ou as quantidades diminuíram. Além disso, como ressalta o autor, uma diminuição na quantidade de comércio ou uma elevação nos preços são condições necessárias, mas não suficientes para que seja consolidada a prática de conluio.

Com relação à economia brasileira, os resultados encontrados por Miranda (2003) diferem dos de Prusa (1999). Miranda (op. cit.) estimou um modelo econométrico para verificar o impacto das medidas antidumping (AD), abertas pelos EUA, sobre o fluxo comercial. No entanto, seu trabalho (diferentemente do de Prusa (1999)) foi basea-
9 Para exemplos de outros sistemas simultâneos de oferta e demanda de sistemas de comércio internacional, ver Goldstein e Khan (1978). 
do na hipótese de país pequeno ${ }^{10}$ para a estimação dos efeitos das investigações $\mathrm{AD}$ sobre as importaçóes dos países citados e náo citados nos processos de investigação. Consideraram-se apenas os casos em que foram aplicados direitos antidumping definitivos e aqueles encerrados sem aplicação de medidas $\mathrm{AD}$ definitivas. O objetivo final era quantificar o efeito líquido sobre as exportaçôes brasileiras para os EUA, no período analisado. Os efeitos fixos associados aos setores aos quais pertencem os produtos citados foram captados também por meio de variáveis binárias, para cada uma das seçóes do $\mathrm{SH}$ que tiveram produtos alvo de investigação.

Os resultados revelaram efeitos negativos sobre as exportaçóes dos países citados, mesmo quando as investigações foram encerradas sem a aplicação de medidas AD. Esse impacto se inicia ainda durante o ano de abertura e é verificado até três anos depois. Tais resultados, porém, não apontam para ocorrência de desvio de comércio, diferentemente do esperado. As estimativas do impacto das medidas AD sobre as exportaçóes brasileiras envolvidas nesses processos indicaram perda em torno de US\$268 milhóes, entre 1992 e 1998. Por fim, o autor afirma que as mudanças nas correntes de comércio podem ocorrer antes da aplicação do direito antidumping.

Este último resultado de Miranda (2003) estaria em consonância com o de Staiger e Wolak (1994), que, em análise da experiência norte-americana na aplicação do mecanismo antidumping, registraram a existência de impactos já durante o período de investigação, bem antes da determinação final a respeito

Markwald (1983), a
formulaçáo teórica para a
especificação do comércio
internacional para uma
economia de grande porte
indica que a oferta e a
demanda por exportação não
são funçóes infinitamente
elásticas do preço, e
sua estimação requer a
resoluçáo do problema da

10 Segundo Braga e

Markwald (1983), a

formulação teórica para a especificação do comércio internacional para uma economia de grande porte indica que a oferta e a demanda por exportação não são funçóes infinitamente sua estimação requer a resolução do problema da identificação causada pela determinação simultânea de preço e quantidade. Uma simplificação dessa hipótese pode ser a adoção da hipótese da economia pequena, em que o volume de comércio de um país depende apenas de suas condiçóes internas. Zini (1988) argumenta que os estudos econométricos sobre as exportaçóes no Brasil têm se concentrado na estimação de funçóes de oferta, com base na hipótese de país pequeno. Essa hipótese pode ser facilmente utilizada para o caso da produçáo siderúrgica brasileira. Comparando os dados do Instituto Brasileiro de Siderurgia (IBS) com os do International Iron and Steel Institute (IISI), constatou-se que a produção nacional oscilou sempre próxima de $3 \%$ do montante produzido mundialmente, entre 1995 e 2006. Portanto, pode-se admitir que o Brasil, e consequentemente o Estado de Minas Gerais, é um tomador de preços no mercado internacional de aço e ferro. 
do dano e da prática de dumping. Isso foi denominado pelos autores de "efeito investigação". ${ }^{11}$

Costa e Burnquist (2004), baseados em Gardner (1987), verificaram o impacto da variação de tarifas nos preços e quantidades exportadas de açúcar pelo Brasil, que tinham como destino os EUA e a União Europeia. O modelo permitiu analisar os efeitos de reduçóes $a d v a-$ lorem $^{12}$ nas tarifas de países importadores relevantes no comércio internacional. Para tanto, utilizaram-se duas equaçóes: uma de oferta de exportaçóes e outra de demanda por importaçôes, levandose em conta que ambas dependem dos preços dos produtos exportados/importados. Além disso, considerou-se que o preço interno prevalecente em um país $i$ qualquer é determinado aplicandose uma tarifa sobre o preço de oferta de mercado de um país exportador. Logo, os consumidores do país $i$ pagam o preço de mercado internacional mais uma taxa tarifária.

Os autores estimaram as funções inversas de oferta e demanda, e a elasticidade-preço de oferta, comum para todos os países demandantes, assim como a elasticidade preço de demanda para o país $i$. Nesse caso, uma redução do nível tarifário do país $i$ provoca aumento da quantidade importada por esse país.
Logo, foi estimada uma equação que expressa o efeito de uma variação no nível de tarifa do país $i$ sobre o preço de oferta do produto citado considerado para aquele país.

Os resultados obtidos mostraram que a eliminação do equivalente tarifário das principais medidas protecionistas mantidas pelos EUA aumentaria a exportação brasileira de açúcar bruto para esse país em cerca de $18 \%$, considerando as exportaçóes médias que ocorreram para o mercado norte-americano, entre 1996 e 2002. Já no caso da União Europeia, essa eliminação provocaria aumento de $55 \%$ sobre as exportaçóes brasileiras, considerando a média do mesmo período.

Vasconcelos e Vasconcelos (2005) verificaram se os arquivamentos das investigaçôes antidumping (por parte das empresas peticionárias) sobre as importaçóes realizadas pelo Brasil, oriundas da Argentina, do Canadá e dos EUA, visavam manter acordos colusivos com as firmas estrangeiras do setor de produtos químicos. Inicialmente, os autores investigaram a possível mudança de padrão das variáveis quantidade e preço unitário das importações em dois períodos de tempo distintos: pré-abertura do processo e pósarquivamento da investigação. Posteriormente, incluíram algumas variáveis de

\footnotetext{
11 Uma vez aberta a investigação, as firmas citadas podem modificar seus preços, a fim de minimizar eventuais penalidades futuras sobre sua conduta atual.

12 Tarifa determinada sobre o valor declarado das mercadorias importadas, em geral sob a forma de percentagem desse valor.
} 
controle na análise como câmbio, renda interna e preços de produtos substitutos.

Os resultados da primeira etapa indicaram redução estatisticamente significativa na importação do produto proveniente dos países envolvidos na investigação. Entretanto, o preço não apresentou o comportamento esperado para colusão, ou seja, não houve aumento pós-arquivamento da mesma. $\mathrm{Na}$ segunda etapa, ao contrário da abordagem inicial, os resultados assinalaram que o pedido de arquivamento do processo de investigação de dumping não teve efeitos no fluxo comercial, não sendo possível afirmar que as firmas nacionais utilizaram o instrumento de medida antidumping como mecanismo de sustentação de acordo colusivo com as empresas estrangeiras.

Cabe ressaltar que, além dos impactos sobre as correntes de comércio, os estudos sobre antidumping abordam extensa lista de temas teóricos e empíricos que incluem colusão, formação de cartéis, economia do bem-estar, integração regional, tarifa ótima, captura, seleção adversa, concorrência imperfeita, custos de transação, economia política da proteção, etc. Esses estudos registram os danos que as medidas antidumping podem causar à economia doméstica através de distintos mecanismos, como: o fortaleci- mento de barreiras à entrada de produtos e o abuso de posiçáo dominante e condutas oportunistas das firmas afetadas pela investigação.

Apesar dessas evidências, são raros os trabalhos que procuram medir o efeito líquido de tais distorçôes sobre o conjunto da economia, lacuna que resulta de dificuldades metodológicas. A principal delas é que as açôes antidumping sempre se referem a produtos incluídos em posições tarifárias definidas a oito dígitos do Sistema Harmonizado, e, em geral, são bens consumidos por um grande número de indústrias. Portanto, é necessário aplicar modelos econométricos bem desagregados, capazes de medir com alguma precisão os impactos de variação de preços de produtos específicos sobre o conjunto da economia, e, simultaneamente, delimitar os setores afetados. Além disso, é indispensável coletar informaçóes minuciosas sobre todos os casos vigentes no país numa determinada data (Blonigen; Prusa 2001).

\section{4_Método}

\section{1_Integração do modelo econométrico com as matrizes de insumo-produto}

Como se verificou anteriormente, não foram encontrados, na literatura revista 
até então, trabalhos que integrassem a abordagem econométrica com a abordagem de insumo-produto (I-P) na análise dos impactos setoriais de medidas antidumping. Desta forma, a presente seção procura estabelecer alguns entendimentos teóricos acerca da integração dos modelos econométricos com as matrizes de I-P.

Existem várias vantagens decorrentes da integração do modelo econométrico com as matrizes de insumo-produto. De acordo com Rey (1998), há motivaçôes para se integrar um modelo econométrico a um modelo de insumoproduto (denominado de modelo IP), uma vez que ambos os métodos separadamente possuem limitaçóes, tais como o fato de o modelo IP assumir função de produção linear, retornos constantes de escala, função consumo homogênea e preços inflexíveis. Mas, quando tais modelos são integrados, algumas dessas limitaçóes são amenizadas, e, além disso, evita-se a crítica de a demanda final ser determinada ad hoc.

Os modelos de IP são essencialmente moldados em equilíbrio geral entre os mercados. Isso ocorre porque o modelo fornece ajustamentos para projeções na demanda, enquanto os preços não influenciam nas respostas. Por outro lado, os modelos econométricos (de agora em diante, denominados "mode- lo EC") frequentemente moldam a economia regional em um contexto de desequilíbrio e/ou equilíbrio parcial em que o foco é normalmente a trajetória do ajustamento da economia para choques exógenos. Contudo, apesar dessa diferença, segundo Beaumont (1990), o importante é que ambos os modelos são direcionados para a demanda, quando aplicados para a economia regional.

Algumas das diferenças entre os modelos têm servido de motivação para combinar os modelos EC e IP. Especificamente, a rigidez de preços do modelo IP tem sido o canal de múltipla integração entre os componentes EC e IP. Isto é, no modelo IP, os coeficientes não são afetados pelos preços; já no modelo integrado, poderá haver mudanças nesses. Desse modo, a abordagem integrada representa melhoria com relação aos modelos tradicionais de EC e IP no que diz respeito ao tratamento dos agregados macroeconômicos (Hewings; Jensen, 1986 apud Rey, 2000).

Guilhoto (2004) argumenta que os modelos econométricos de insumoproduto visam, por um lado, tirar vantagem do poder de previsão dos modelos econométricos e, por outro, tirar vantagem dos aspectos intersetoriais e interregionais encontrados nos modelos de insumo-produto. 
Tabela 3_Comparativos das características entre os modelos IP, EC e EC+IP

\begin{tabular}{|c|c|c|c|}
\hline Características & IP & EC & $\mathrm{EC}+\mathrm{IP}$ \\
\hline Dinâmico & não & sim & $\operatorname{sim}$ \\
\hline Desagregado & $\operatorname{sim}$ & nâo & $\operatorname{sim}$ \\
\hline Sensível a preço & não & $\operatorname{sim}$ & sim \\
\hline Análise de impacto & $\operatorname{sim}$ & $\operatorname{sim}$ & $\operatorname{sim}$ \\
\hline Direcionado para a demanda & $\operatorname{sim}$ & $\operatorname{sim}$ & $\operatorname{sim}$ \\
\hline Previsão & não & $\operatorname{sim}$ & $\operatorname{sim}$ \\
\hline Inferência & não & $\operatorname{sim}$ & Indefinido \\
\hline Multirregional & $\operatorname{sim}$ & $\operatorname{sim}$ & Indefinido \\
\hline
\end{tabular}

Nota: A utilização de modelos EC+IP para inferência e contextos multirregionais deve ser tratada com cuidado. No caso da inferência, as criticas surgem da utilização conjunta de um modelo determinístico, sem nenhum tipo de incerteza associada, como é o caso do IP, com um modelo desenvolvido para lidar com a incerteza, caso do EC. Quanto a análise multirregional, argumentase que, embora ambos possam ser utilizados para tal análise, fica difícil definir qual destes modelos capta melhor as ligaçóes interregionais (Rey, 1999. p.6).

Por sua vez, Rey (2000) destaca três motivaçôes práticas na utilização dos modelos EC+IP, a saber: (a) aprimoramento no desempenho da previsão, que resulta em melhores inferências sobre as relaçóes interindustriais na região; (b) maior preocupação com erros de medida (podemse citar, por exemplo, testes de hipóteses e níveis de confiança); e (c) aperfeiçoamento das projeçóes em termos de alcance e a capacidade de análise da previsão, se comparado com cada modelo separadamente.

Entretanto, uma limitação reconhecida nos modelos de IP na análise de previsão é que a trajetória do tempo pa- ra estimar as variaçóes através da economia regional não é mutável. Isso ocorre em razão da estática comparativa natural desse modelo. Os modelos econométricos, em contraste, têm na dinâmica sua principal característica de capacidade de analisar projeçóes. Por outro lado, os modelos EC são muito mais agregados que os modelos IP. No entanto, ao combinar os dois em EC+IP, a dinâmica e a desagregação industrial podem ser desenvolvidas. Na Tabela 3, é apresentado um resumo das principais características dos modelos econométricos (EC) e do insumo-produto (IP) supracitados. 
Um grande número de modelos integrados tem sido implementado em economia regional. Portanto, há uma quantidade razoável de métodos que podem ser usada para integrá-los. Segundo Rey (1998), a estratégia de integração é definida pela maneira e extensão com a qual os componentes dos modelos EC e IP serão combinados em um conjunto final. Há três maneiras de integrar o modelo EC+IP: (i) Ligação (linking); (ii) Determinação mútua (embedding); e (iii) Acoplagem (coupling). Na estratégia de ligação, um dos módulos (EC ou IP) é exógeno ao outro, de forma que a interação entre eles é recursiva; nas estratégias de determinação mútua e de acoplagem, os módulos apresentam retroalimentação simultânea entre si, com o mecanismo de retroalimentação podendo ser completo (determinação mútua) ou parcial (acoplamento).

A construção do modelo EC+IP utilizado neste trabalho seguiu a estratégia de integração por ligação. De acordo com Rey (1999), a estratégia de ligação usada para integrar os modelos EC e IP pode ser de duas maneiras. Podese empregar a forma IP se ligando a EC, $(I P \Rightarrow E C)$, que consiste em utilizar algum componente da matriz IP como variável do modelo EC. A outra forma de integração é aquela em que o módulo
EC se liga ao IP $(E C \Rightarrow I P)$. Neste caso, a previsáo dos agregados macroeconômicos é especificada como endógena. Isto é, após a especificação e a estimação do modelo EC, utilizam-se esses resultados na composição ou na especificação de algum vetor do modelo IP.

Neste artigo, adotou-se a estratégia em que o módulo EC liga-se ao módulo IP. Desta forma, pode-se mensurar o impacto de choques adversos de medidas antidumping sobre as exportaçóes nacionais via modelo econométrico. Com base nesses resultados (empregando o link $(E C \rightarrow I P)$, é possível inferir sobre o efeito desses choques nas exportaçóes sobre produção, renda e emprego tanto no setor analisado quanto para a economia como um todo. Tal processo permite que o "choque" dado no módulo IP (especificamente no vetor de demanda final no componente de exportaçóes) seja não aleatório (ou ad hoc), uma vez que será utilizado o resultado do modelo EC.

\section{2_ 0 modelo econométrico}

Para a análise dos impactos das medidas antidumping, inicialmente se buscou identificar uma possível quebra estrutural nas exportações mineiras de aço laminado a quente (PALQ), com destino aos 
EUA. Para tanto, empregou-se a seguinte relação log linear: ${ }^{13}$

$\operatorname{Ln}(X)=a(C)+b(D D P)+\varepsilon$

onde, $\operatorname{Ln}(X)$ é o logaritmo natural das exportaçóes de PALQ oriundas de MG com destino aos EUA, no período de janeiro de 1995 a dezembro de 2002; (C) representa uma constante do modelo; $(D D P)^{14}$ é a dummy de direito provisório, com valores iguais a 1, de janeiro de 1995 a janeiro de 1999 , e iguais a 0 , de fevereiro de 1999 a dezembro de 2002; $\varepsilon$ é o termo de erro; $a$ e $b$ são os coeficientes das respectivas variáveis. Espera-se que o sinal do coeficiente $b$ seja positivo, confirmando que, no período anterior à medida $\mathrm{AD}$, as exportaçóes oscilavam em níveis superiores.

\footnotetext{
13 Neste caso, em que a variável dependente está em log, a interpretação do coeficiente da dummy como mudança percentual segue a abordagem de Halversen e Palmquist (1980), ou seja, antilog na base $e$ menos um.

14 Utilizou-se também outra dummy (DA), sobre esse modelo, para testar a hipótese de "efeito investigação". Pode ter ocorrido diminuição no fluxo comercial mesmo antes de uma medida ter sido adotada, apenas com
}

\author{
a abertura do processo, \\ ocorrido em 22/10/1998. Essa \\ dummy também se mostrou \\ significativa. Logo, pode-se \\ concluir que as exportaçóes \\ diminuíram mesmo antes \\ de alguma medida ser \\ efetivamente adotada. Mais \\ sobre efeito investigação, em \\ Prusa (1996 e 1999). \\ 15 Para mais especificaçóes \\ sobre estimação de equaçóes \\ de demanda e oferta de \\ exportaçóes, veja: Carvalho \\ e De Negri (2000) e \\ Portugal (1992).
}

Uma vez comprovado o efeito da aplicação do direito antidumping, devese partir para a estimação de modelo de função oferta de exportação incorporando variáveis macroeconômicas, objetivando captar a influência dessas variáveis sobre as exportaçóes de Minas Gerais. Nessa etapa, a formulação da equação do modelo econométrico proposto será dado na forma $\log -\log ^{15}$ abaixo:

$$
\begin{aligned}
\operatorname{Ln}(X)= & a_{0}+a_{1} \ln C+a_{2} \ln Y^{p}+a_{3} \ln Y+ \\
& +a_{4} \ln Y^{*}+a_{5} D+\mu
\end{aligned}
$$

onde $X$ representa a série histórica mensal de exportaçóes de produtos de aço laminados a quente de Minas Gerais para os EUA; $C$ é a taxa de câmbio real definida como $(E P x / P d)$, sendo $E$ a taxa de câmbio nominal (R \$ US\$) mensal entre Brasil e EUA; $P x$, o preço unitário mensal dos produtos de aço laminados a quente exportados de Minas Gerais para os EUA; e $P d$, o preço dos bens domésticos; $Y^{p}$ é a capacidade instalada da indústria; $Y$ e $Y^{*}$ são o nível de produção interna e externa, respectivamente; $D$ é a variável dummy para o período de abertura da petição, assumindo valores 1 antes desta e 0 após; $\mu$ é o termo de choque exógeno. Todas as variáveis têm periodicidade mensal e compreendem o período de janeiro de 1995 a dezembro de 2002. 
Para estimar a equação (2), referente às exportaçôes do setor siderúrgico do Estado de Minas Gerais para os EUA, entre o período de 1995 a 2002, foi utilizada a abordagem de cointegração via modelos autorregressivos de defasagem distribuída - ARDL -, como proposto por Pesaran et al. (2001). Essa abordagem é similar ao modelo de correção de erros padrão, com a diferença de que se emprega uma combinação linear das variáveis em nível defasadas em um período, em vez de utilizar a inclusão do termo de erro defasado de uma equação de cointegração. ${ }^{16}$ Desta forma, o modelo ARDL difere de um modelo de vetores autorregressivos - VAR -, padrão que inclui as variáveis na forma defasada. Assim, formalmente a especificação do modelo fica:

$$
\begin{aligned}
\Delta \ln X & =\alpha_{0}+\sum_{i=1}^{n} b_{i} \Delta \ln X_{t-i}+ \\
& +\sum_{i=0}^{n} c_{i} \Delta \ln C_{t-i}+ \\
& +\sum_{i=1}^{n} d_{i} \Delta \ln Y_{t-1}^{P}+ \\
& +\sum_{i=0}^{n} e_{i} \Delta \ln Y_{t-i}+ \\
& +\sum_{i=0}^{n} f_{i} \Delta \ln Y_{t-1}^{*}+ \\
& +\delta_{1} \ln X_{t-1}+\delta_{2} \ln C_{t-1}+
\end{aligned}
$$

$$
\begin{aligned}
& +\delta_{3} \ln Y_{t-1}^{P}+\delta_{4} \ln Y_{t-1}+ \\
& +\delta_{5} \ln Y_{t-1}^{*}+D_{t}+\mu_{t}
\end{aligned}
$$

onde $X$ são as exportações de produtos de aço laminados a quente de Minas Gerais para os EUA; $C$ é a taxa de câmbio real; $Y^{P}$, a capacidade instalada da indústria; $Y$ é o nível de produção interna; $Y^{*}$ é o nível de produção externa; $D$ é a variável dummy para o período de abertura da petição, assumindo valores 1 antes desse e 0 após; $\mu$ é o termo de choque aleatório.

A abordagem do "teste de fronteira para cointegração" de Pesaran et al. (2001) apresenta a característica de não ser necessária a verificação da ordem de integração das variáveis, ou seja, se elas são estacionárias em nível, I(0), ou estacionárias na primeira diferença, I(1). Portanto, o modelo prescinde da análise de estacionariedade para a análise da cointegração das séries.

O procedimento adotado envolve dois estágios. Primeiramente, mediante um teste de adição de variáveis, foi verificada a existência de relação de longo prazo entre as variáveis defasadas da equação 3. Nesse caso, a hipótese nula é de não existência de cointegração, isto é, $\mathrm{H}_{0}: \delta_{1}=\delta_{2}=\delta_{3}=\delta_{4}=\delta_{5}=0$, contra a hipótese alternativa $H_{1}: \delta_{1} \neq \delta_{2} \neq \delta 3 \neq \delta 4 \neq$
16 Isto é, o termo $\mu_{t-1}$ estimado na equação 2 . 
17 Isto é, se o valor calculado da estatística $F$ for maior que o valor crítico da banda inferior e menor que o valor da banda superior.

18 Cabe ressaltar que a variação no vetor de exportaçōes é proveniente do modelo econométrico e incorpora choques apenas na célula referente ao setor siderúrgico de Minas Gerais. Esse choque gera impactos indiretos sobre os demais setores do Estado e do restante do país. $\neq \delta 5 \neq 0$. Pesaran (op. cit.) mostra que isso pode ser feito por meio de um teste $F$. Como, porém, a estatística $\mathrm{F}$ calculada não apresenta a distribuiçáo padrão, novos valores críticos são tabulados e apresentados por Pesaran et al. (2001). Dois conjuntos ou bandas de valores críticos são apresentados pelos autores, e um deles assume que todas as variáveis do modelo ARDL são $\mathrm{I}(0)$, e o outro, que todas são I(1). Se a estatística $F$ calculada for maior que o valor crítico da banda superior (valores críticos para variáveis $\mathrm{I}(1)$ ), rejeita-se a hipótese nula (ou seja, as variáveis cointegram). Caso o valor calculado seja menor que o valor crítico da banda inferior, a hipótese nula náo pode ser rejeitada, não evidenciando cointegração.

Por fim, se o valor da estatística F calculado estiver dentro do intervalo estabelecido pelas bandas, ${ }^{17} \mathrm{o}$ resultado é inconclusivo. Neste caso específico, a utilização posterior de um Modelo de Correção de Erros possibilitaria evidenciar a existência ou não da relaçáo de longo prazo entre as variáveis (cointegração), como salienta Banerjee et al. (1998).

Confirmada a relação de longo prazo entre as variáveis, o segundo passo da análise foi estimar um modelo de correção de erros - ECM -, com base no modelo de ARDL, para estabelecer a dinâmica de curto prazo entre as variáveis.

\section{3_Impactos das exportações do setor siderúrgico de Minas Gerais sobre a produção e o emprego na matriz I-P}

A fim de verificar os impactos de variaçôes nas exportações do setor siderúrgico (obtidas no módulo econométrico) sobre o produto e emprego, fez-se necessária a desagregaçáo da demanda final (componente Y) da matriz de IP. Em outras palavras, foi preciso explicitar as exportaçóes para que fosse possível implementar o choque nesse componente e, entáo, calcular os impactos sobre a economia. Assim,

$X=B[C+I+G+E]$

onde: $X$ é o vetor de valor bruto da produção setorial; $B$ é a matriz de Leontief; $C$ representa o vetor de consumo setorial das famílias; $I$, o vetor de investimento setorial; $G$, o vetor dos gastos setoriais do governo; $E$ o vetor de exportaçóes setoriais. A partir da equação (4), implementou-se o seguinte exercício de simulação:

$$
\begin{aligned}
& \Delta X=B(\Delta Y) \\
& \Delta Y=C+I+G+\Delta E
\end{aligned}
$$

Portanto, a variação da demanda final $(Y)$, será dada pelas mudanças ocorridas nas exportaçóes (vetor E), ${ }^{18}$ mantendo-se os demais termos constantes. No entanto, como o intuito deste trabalho é analisar o efeito de variaçóes na demanda final, decorrentes de mudanças 
nas exportações, sobre o produto e o emprego dos setores de Minas Gerais e no restante do Brasil, foi desenvolvido um método para captar cada um desses efeitos. O impacto sobre a produção foi medido da seguinte forma: ${ }^{19}$

$\Delta X=(I-A)^{-1} * \Delta E$

onde $\Delta E$ é o vetor de exportações setoriais (variação anual oriunda do modelo econométrico); $\Delta X$ representa o impacto das exportações na produção; $(I-A)^{-1}$ constitui a matriz inversa de Leontief.

Com relação ao impacto sobre o emprego, decorrente de variaçóes no vetor de exportaçôes, o cálculo seguiu os seguintes passos:

a) Construção de vetores de coeficientes diretos de emprego, para os anos de 1999, 2000, 2001 e 2002, como segue:

$e_{j ; z}=\frac{P O_{j ; z}}{X_{j ; z}}$

$O$ vetor em (7) é a razão entre o pessoal ocupado, $P O$, no ano $z$ para cada setor $j$, e o valor bruto da produção, ou demanda total $X$ de cada um dos setores no respectivo ano.

b) Estimação do vetor de pessoal ocupado, por setor para os anos de 1999 a 2002. Estes vetores $\left(e_{j}\right)$ serão multiplicados pelo valor da demanda total, estimada pelo modelo econométrico (que adota a hipótese de que nenhuma medida antidumping foi utilizada contra a siderurgia de Minas Gerais). Ou seja:

$P O(\text { Estimado })_{\mathrm{j} ; \mathrm{z}}=X(\text { Estimado })_{\mathrm{j} ; \mathrm{z}}{ }^{*} e_{\mathrm{j} ; \mathrm{z}}$

Em que o PO (estimado) é o número de empregados no setor $j$, referente ao ano $z$, considerando o vetor real de coeficientes diretos de emprego, $e_{j ; z}$, caso as exportaçóes da siderurgia não tivessem sido oneradas com medidas restritivas. Isto é, caso a demanda total, $X$, para cada setor, obtida no modelo econométrico, seja incorporada no modelo.

Como mencionado, a construção do modelo EC+IP utilizada neste trabalho seguiu a estratégia de integração por ligação, na qual o módulo EC se liga ao módulo IP e não há feedback. Desta forma, a variação percentual obtida no modelo econométrico foi incorporada no total exportado pelo setor siderúrgico do Estado de Minas Gerais e inserida no setor siderúrgico da matriz intersetorial (MG x Restante do Brasil) de I-P nos anos de 1999, 2000, 2001 e 2002. Tais resultados possibilitarão a análise dos impactos intersetoriais gerados para Minas Gerais e o restante do Brasil, no que se refere ao produto e ao emprego (Figura 1).
19 A mensuraçáo dos impactos no produto podem ser obtidas em Miller e Blair (2009),

Isard et al. (1998) ou Perobelli et al. (2006). 
Figura 1_Resumo dos procedimentos metodológicos adotados
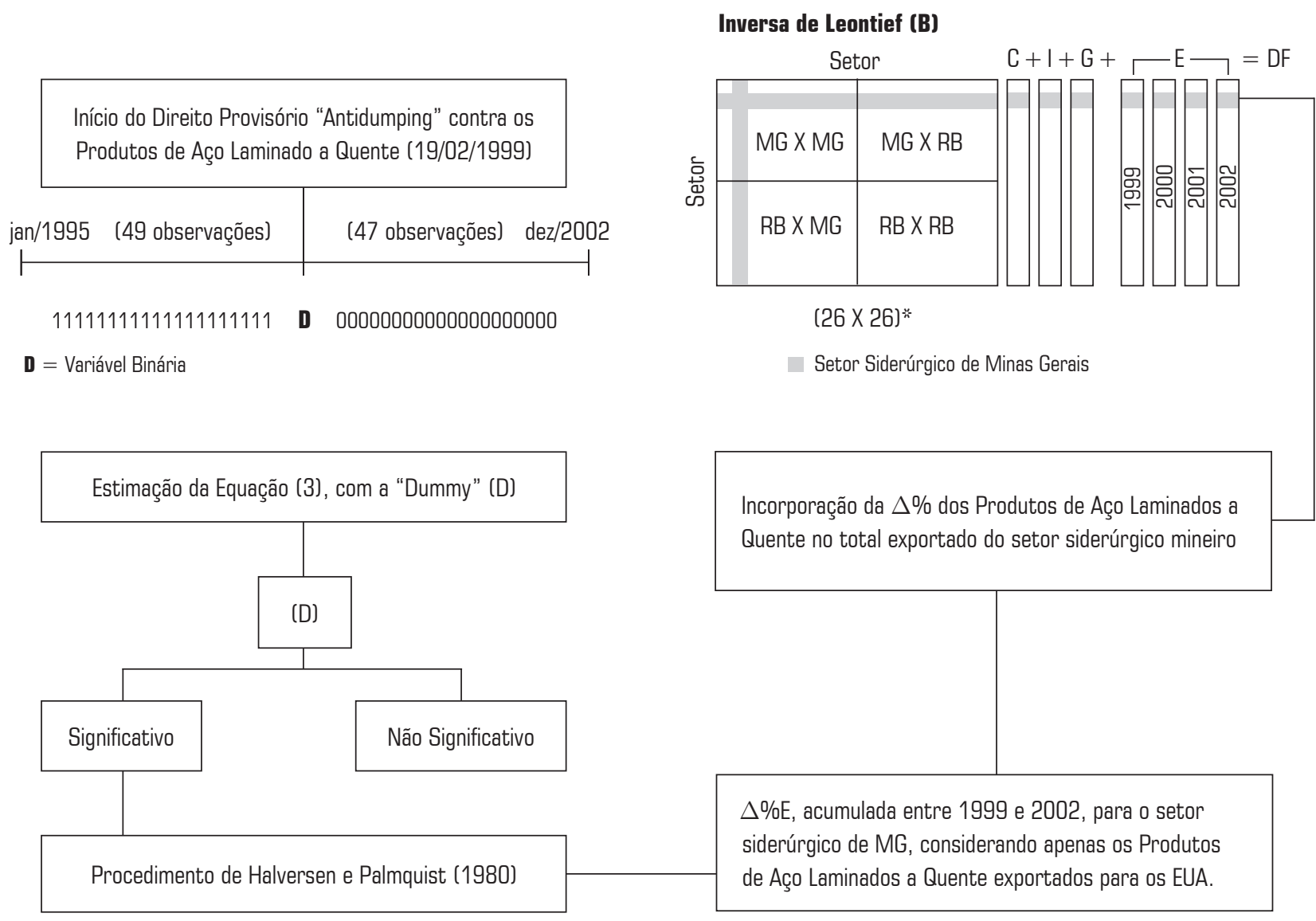

Incorporação da $\Delta \%$ dos Produtos de Aço Laminados a Quente no total exportado do setor siderúrgico mineiro

*As matrizes inter-regionais utilizadas, para os anos de 1999 a 2002, apresentam desagregação para 13 setores em de Minas Gerais e no restante do Brasil. Logo, é possível captar os efeitos diretos e indiretos provenientes de variações nas exportações do setor siderúrgico de Minas Gerais nos setores de ambas as regiões.

Fonte: Elaboraçấo própria. 


\section{4_Atualização das matrizes - metodologia RAS}

Miller e Blair (2009) desenvolveram um método de atualização dos dados de matrizes passadas que consiste primeiro em definir os consumos intermediários, pela ótica das compras e das vendas, para, em seguida, implementar o ajuste biproporcional, RAS, ${ }^{20}$ na construção das transaçóes econômicas intersetoriais e intrassetoriais. Deste modo, é necessário que se conheça os vetores de demanda total e de consumo intermediário (pela ótica das vendas e das compras) na estimativa dos coeficientes técnicos atualizados (para Minas Gerais e Restante do Brasil, no caso deste trabalho).

Neste método, são necessários os vetores representantes do total de vendas interindustriais de cada um dos setores da matriz, U(1), e das compras interindustriais dos mesmos setores da matriz, $\mathrm{V}(1)$, além do o vetor de produção total, $\mathrm{X}(1)$ e os coeficientes técnicos da matriz de insumo-produto base, ${ }^{21} \mathrm{~A}(0)$. Os termos (1) e (0) representam valores para o ano alvo e ano-base, respectivamente.

$\mathrm{O}$ primeiro passo foi testar se $\mathrm{A}(0)$ $=A(1)$, ou seja, se os coeficientes técnicos seriam estáveis. Assim, se a soma de cada uma das linhas e colunas da matriz $[A(0) \hat{X}(1)]$, que resultarão em vetores denominados $\mathrm{U}^{0}$ e $\mathrm{V}^{0}$, for igual a $\mathrm{U}(1)$ e V(1), respectivamente, o ajuste estará terminado. Portanto, os coeficientes da matriz base, $\mathrm{A}(0)$, em conjunto com o novo produto do ano alvo X(1), gera a própria matriz interindustrial.

Todavia, geralmente $\mathrm{V}^{0} \neq \mathrm{V}(1)$ e $\mathrm{U}^{0} \neq \mathrm{U}(1)$. Assim, o segundo passo foi contornar tal problema do vetor $U$, criando outro vetor de ajuste, na forma: $\mathrm{U}(1) / \mathrm{U}^{0}$, representado por $R^{1}$. Os elementos da matriz $\mathrm{A}(0)$ são multiplicados por esse vetor diagonalizado, na forma matricial $A^{1}=\hat{R}^{1} A(0)$, formando um novo conjunto de coeficientes técnicos os quais, se multiplicados por $\mathrm{X}(1)$, são ajustados para atingir os valores de $\mathrm{U}(1)$.

$\mathrm{O}$ mesmo procedimento foi realizado nas colunas (vetor V). Neste caso, utilizou-se o vetor $\mathrm{V}(1) / \mathrm{V}^{0}$, representado por $S^{1}$, para corrigir as diferenças entre $\mathrm{V}(1)$ e $\mathrm{V}^{1}$. Assim, o resultado desse procedimento é dado por:

$A^{2}=\hat{R}^{1} A(0) \hat{S}^{1}$

onde "A" representa a matriz de coeficientes técnicos $\hat{R}$ é uma matriz diagonal que modifica as linhas da matriz $\mathrm{A}(0)$, e $\hat{S}$ é uma matriz diagonal que modifica as colunas da mesma matriz. Os valores sobrescritos representam o número de vezes que as matrizes foram modificadas. $\mathrm{O}$ valor 0 (zero) representa a matriz ano-base. Da equação 9, deri-
20 Outros autores que utilizaram esse método foram: Haddad e Domingues (2003), Porsse et al. (2003) e Souza (2008).

21 Neste trabalho, os coeficientes foram obtidos da matriz inter-regional (MG x RB) para 1996 (ver seção "Base de Dados"). 
vou-se o nome "RAS" da metodologia. Esse processo deve ser repetido quantas vezes forem necessárias $\left(\mathrm{A}^{3}, \mathrm{~A}^{4} \ldots \mathrm{A}^{\mathrm{k}}\right)$ até que os valores encontrados sejam iguais a $U(1)$ e $V(1)$.

\section{5_Fonte e natureza dos dados}

A base de dados foi composta de quatro matrizes inter-regionais de insumo-produto para o Estado de Minas Gerais e o restante do país (MG x Restante do Brasil), referentes aos anos de 1999 a 2002. Neste caso, foram utilizadas as matrizes

\footnotetext{
22 A data indicada para o IBGE, 20 de Novembro de 2007, refere-se ao ano de acesso de Souza (2008) a estes dados. Uma vez que tais dados foram utilizados pelo autor supracitado para atualizar as matrizes interregionais utilizadas neste trabalho.

${ }^{23}$ Necessários para a implementação da metodologia RAS.

${ }^{24}$ Cabe ressaltar que as matrizes atualizadas por Souza (2008) e utilizadas aqui apresentavam desagregação para apenas 13 setores. Portanto, precisaram-se compatibilizar os dados do IBGE (2007) com esses
}

\author{
setores das matrizes. Porém, \\ os setores de Minerais Não \\ Metálicos, Ferro e Aço, \\ Metais Não Ferrosos e outras \\ Metalurgias, Papel e Celulose, \\ Química, Alimentos e \\ Bebidas, Têxtil e Vestuário \\ e Outras Indústrias das \\ Matrizes de Souza (2008) \\ encontravam-se agregadas \\ em quatro grupos no IBGE \\ (2007). São eles: Indústria \\ da Transformação, SIUP, \\ Construção e Comunicações. \\ Logo, o somatório desses \\ quatro setores, para os seus \\ respectivos anos, foram \\ redistribuídos nas matrizes de \\ Souza (2008), de acordo com \\ a participação verificada na \\ matriz-base de 1996 (BDMG; \\ FIPE, 2002).
}

atualizadas por Souza (2008). Para tanto, o autor empregou a matriz de insumoproduto inter-regional (MG x Restante do Brasil), referente ao ano de 1996 (BDMG; FIPE, 2002), como matriz-base. Além disso, foram utilizados dados das contas nacionais e regionais disponibilizados pelo IBGE (2007) ${ }^{22}$ e as matrizes de insumo-produto, estimadas para o Brasil, por Guilhoto e Sesso Filho (2005), referentes aos anos de 1997 a 2002.

Para a construção dos consumos intermediários pela ótica das compras e vendas, ${ }^{23}$ inicialmente se utilizou ótica das compras na construção dos vetores de demanda total e valor adicionado, empregando-se os dados do IBGE (2007). ${ }^{24}$ Uma vez realizado esse processo, tais vetores foram distribuídos percentualmente e ponderados pelos valores disponíveis na matriz de Guilhoto e Sesso Filho (2005). Portanto, cada matriz atualizada está expressa em valores correntes.

Ainda considerando a ótica das compras, passou-se para a construção do vetor de impostos e importações. Neste caso, foi utilizada a estrutura percentual encontrada na matriz de insumo-produto inter-regional de 1996 (BDMG; FIPE, 2002). Em seguida, esses valores foram redistribuídos, setorialmente, de acordo com o valor disponível na matriz de Guilhoto e Sesso Filho (2005). Assim, a 
subtração do valor adicionado, impostos e importaçóes da demanda total revelam o consumo intermediário sob a ótica das compras.

Em seguida, empregando a abordagem da ótica das vendas, procedeu-se a construção de um vetor de demanda final. Para tanto, a demanda final foi desagregada em vetores de absorção interna onde estão inseridos consumo privado, gastos públicos e formação bruta de capital fixo. Esse vetor foi construído com base na matriz de 1996 (BDMG; FIPE, 2002) e ponderado com os valores disponíveis na matriz de Guilhoto e Sesso Filho (2005) para os anos de 1999 a 2002. Na sequência, foi construído o vetor de absorção externa ou exportaçóes. Para tanto, compatibilizaram-se os setores das matrizes de Guilhoto e Sesso Filho (2005), que contêm dados nacionais, com a matriz agregada de Souza (2008). Logo após, o total de exportação de cada setor da matriz de Guilhoto e Sesso Filho (2005) foi distribuído entre Minas Gerais e o restante do Brasil, de acordo com a proporção apresentada na matriz inter-regional de 1996 (BDMG; FIPE, 2002). O consumo intermediário pela ótica das vendas foi obtido mediante a subtração dos vetores de absorção interna e externa do vetor de demanda total. Uma vez realizadas essas etapas, foi possível atualizar as matri- zes inter-regionais, para os anos de 1999 a 2002, utilizando-se a metodologia RAS.

O número de pessoas ocupadas, por setor, em Minas Gerais e no restante do Brasil, foi obtido na Relação Anual de Informaçóes Sociais - RAIS disponibilizadas pelo Ministério do Trabalho e Emprego - MTE (Brasil/MTE/RAIS, 2009). ${ }^{25}$

Já a natureza e a fonte dos dados (mensais) referentes à função de exportação do modelo econométrico é a seguinte: as exportaçóes de produtos de aço laminados a quente (PALQ) oriundos de Minas Gerais para os EUA, bem como o preço unitário dos produtos exportados, foram obtidas no Sistema ALICEweb, disponíveis em Brasil/MDIC/ ALICEweb (2008) ${ }^{26}$ A série histórica da taxa de câmbio mensal entre os países foi

\begin{tabular}{|c|c|}
\hline \multirow{7}{*}{$\begin{array}{l}25 \text { Neste caso, utilizou-se o } \\
\text { número de trabalhadores com } \\
\text { carteira assinada que estavam } \\
\text { trabalhando no dia } 31 \text { de } \\
\text { dezembro, nos anos de } 1999 \\
\text { a } 2002 \text {. }\end{array}$} & \multirow{7}{*}{$\begin{array}{l}\text { do sistema harmonizado } \\
\text { da Nomenclatura Comum } \\
\text { do Mercosul (NCM), (até } \\
\text { oito dígitos). São eles: } \\
\text { 72.08; } 7211.1 \text { a } 7211.19 .00 ; \\
7214.20 .00 \text { a } 7214.9 ;\end{array}$} \\
\hline & \\
\hline & \\
\hline & \\
\hline & \\
\hline & \\
\hline & \\
\hline 26 OA PAI & 7216.10 .00 a 7216.50 .00 \\
\hline al & $7219.24 .00 ; 7220.1$ \\
\hline elo & $2.90 ; 7222.1 \mathrm{a}$ \\
\hline & $30.00 \mathrm{a}$ \\
\hline apor essa & 26.91.00; \\
\hline dos do & letalhes \\
\hline & dados da NCM e \\
\hline 201 & de agregação, ver \\
\hline & \\
\hline
\end{tabular}


encontrada no IPEADATA (2008). Para o preço dos bens domésticos, foi usado como proxy o índice de preço por atacado, IPA-DI, da Fundação Getúlio Vargas (IPEADATA, 2008). Com relação ao nível de produto real, utilizou-se o índice quantum da produção industrial do IBGE (IPEADATA, 2008). O índice de produção industrial (no Brasil e nos EUA) e a utilização da capacidade instalada, ambos dessazonalizados, foram obtidos no IPEADATA (2008). Estas duas últimas variáveis tiveram janeiro de 2002 como base. Todos os dados têm periodicidade mensal, iniciando em janeiro de 1995 até dezembro de 2002, como mencionado anteriormente.

\section{5_Resultados}

\section{1_Exportação mineira de produtos de aço laminados a quente: o modelo econométrico}

Inicialmente foi testada a existência de uma quebra estrutural nas exportaçóes de Minas Gerais oriunda da medida antidumping (AD) adotada pelos EUA, contra a siderurgia nacional. $\mathrm{O}$ resultado do modelo com a dummy para a adoção de direito provisório (equação 1) está retratado na Tabela 4. Pode-se notar que houve diminuição nas exportações após a adoção do direto provisório antidumping. A variável dummy foi significativa e com o sinal esperado, dando indícios

Tabela 4_Regressão do modelo com "dummy" após a adoção de direito provisório (fevereiro de 1999) - PALQ

Variável dependente: LNK (PALQ)

Amostra: 1995M01 2002M12

\begin{tabular}{|c|c|c|c|c|}
\hline Amostra: 1995M01 2002M12 & \multicolumn{4}{|c|}{ Variáveis incluídas: 96} \\
\hline Variável & Coeficiente & Erro padrão & Estatística-t & Prob. \\
\hline $\mathrm{C}$ & 14,45840 & 0,105644 & 136,8595 & 0,0000 \\
\hline DDP & 0,646811 & 0,147871 & 4,374158 & 0,0000 \\
\hline $\mathrm{R}^{2}$ & 0,169121 & \multicolumn{2}{|c|}{ Estatística de Durbin-Watson } & 1,502853 \\
\hline $\mathrm{R}^{2}$ Ajustado & 0,160282 & \multicolumn{2}{|c|}{ Estatística F } & 19,13326 \\
\hline Máxima verossimilhança & $-104,2374$ & \multicolumn{2}{|c|}{ Probabilidade (Estatística F) } & 0,000032 \\
\hline
\end{tabular}

Método: Mínimos Quadrados

Variáveis incluídas: 96

Fonte: Cálculos do trabalho. 
Tabela 5_Regressão do modelo com "dummy" após a adoção de direito provisório (fevereiro de 1999) - PALF

Variável dependente: LNK (PALF)

Amostra: 1995M01 2002M12

\begin{tabular}{l|c|c|c}
\hline Variável & Coeficiente & Erro padrão & Estatística-t \\
\hline $\mathrm{C}$ & 14,49408 & 0,142366 & 101,8083 \\
\hline $\mathrm{DDP}$ & $-0,252077$ & 0,201336 & $-1,252022$ \\
\hline $\mathrm{R}^{2}$ & 0,017501 & Estatística de Durbin-Watson \\
\hline $\mathrm{R}^{2}$ Ajustado & 0,006337 & \multicolumn{2}{c}{0,0000} \\
\hline Máxima verossimilhança & $-122,5513$ & Eratística F & 0,861982 \\
\hline ...........................................................................................................................
\end{tabular}

Fonte: Cálculos do trabalho.

de que as exportaçóes de PALQ oscilavam em patamares superiores antes do período em que o direito provisório foi adotado contra as exportaçóes de Minas Gerais com destino aos EUA. ${ }^{27}$

Entretanto, pode-se esperar que, com a imposição de medidas AD contra as exportaçóes brasileiras de laminados a quente, haveria estímulo ao aumento de exportações nacionais de produtos de aço laminados a frio (PALF), produto este que possui maior valor agregado comparativamente a laminados a quente. Logo, investigou-se uma possível mudança estrutural na trajetória de importaçóes dos EUA de produtos laminados a frio com origem em Minas Gerais, no período sob análise.
A hipótese seria a consequência de uma possível mudança do mix de exportaçáo de produtos de aço laminados, advinda de uma diminuição dos PALQs (alvo de medida AD) e crescimento dos PALFs, o que poderia compensar o efeito da medida AD sobre as exportações totais. No entanto, observou-se que o coeficiente da variável dummy, DDP, não foi estatisticamente significativo (Tabela 5). Portanto, o incremento nas exportaçôes (via laminados a frio) não pôde ser comprovado.

Assim sendo, foram incluídas variáveis de controle no modelo estimado (equação 2). Inicialmente, verificou-se a propriedade do método de abordagem proposto na seção anterior através dos
27 O modelo utilizado para verificar a hipótese de "efeito investigação" (com a dummy de abertura de processo $\mathrm{AD}$, em 22/10/1998), também se mostrou altamente significativa. Gerando indícios de que, mesmo antes de uma medida provisória ser adotada, o fluxo comercial já havia sido afetado. No entanto, os maiores efeitos ocorrem após a aplicação do direito provisório. 
Tabela 6_Teste de raiz unitária para as séries da equação 2

\begin{tabular}{|c|c|c|c|c|c|c|c|c|c|c|c|c|}
\hline & \multicolumn{4}{|c|}{ ADF } & \multicolumn{4}{|c|}{ Phillips-Perron } & \multicolumn{4}{|c|}{ KPSS } \\
\hline & \multicolumn{2}{|c|}{ Constante } & \multicolumn{2}{|c|}{$\begin{array}{l}\text { Constante } \\
\text { e tendência }\end{array}$} & \multicolumn{2}{|c|}{ Constante } & \multicolumn{2}{|c|}{$\begin{array}{c}\text { Constante } \\
\text { e tendência }\end{array}$} & \multicolumn{2}{|c|}{ Constante } & \multicolumn{2}{|c|}{$\begin{array}{c}\text { Constante } \\
\text { e tendência }\end{array}$} \\
\hline & Nível & I(1) & Nível & $I(1)$ & Nível & $I(1)$ & Nível & I(1) & Nível & $I(1)$ & Nível & I(1) \\
\hline $\ln X$ & $\begin{array}{r}-4,16 \\
(* * *)\end{array}$ & - & - & - & $\begin{array}{r}-6,90 \\
(* * *)\end{array}$ & - & - & - & $\begin{array}{l}0,75 \\
(* * *)\end{array}$ & - & - & - \\
\hline $\ln C$ & $\begin{array}{c}-2,58 \\
\left(^{*}\right)\end{array}$ & - & $\begin{array}{r}-7,87 \\
(* *) \\
\end{array}$ & - & $\begin{array}{l}6,28 \\
(* * *)\end{array}$ & - & $\begin{array}{r}-8,16 \\
(* * *)\end{array}$ & - & $\begin{array}{l}1,05 \\
(* * *)\end{array}$ & - & 0,10 & - \\
\hline $\ln Y$ & - & - & $\begin{array}{r}-4,05 \\
(* * *)\end{array}$ & - & - & - & $\begin{array}{r}-3,91 \\
(* *)\end{array}$ & - & - & - & 0,11 & - \\
\hline $\ln Y^{*}$ & - & - & 2,56 & $\begin{array}{l}7,33 \\
\left({ }^{* * *}\right)\end{array}$ & - & - & 2,48 & $\begin{array}{l}7,31 \\
(* * *)\end{array}$ & - & - & $\begin{array}{c}0,12 \\
(* *)\end{array}$ & 0,04 \\
\hline $\operatorname{lnYP}$ & $-1,67$ & $\begin{array}{l}-9,31 \\
(* * *)\end{array}$ & - & - & $-1,73$ & $\begin{array}{l}-9,31 \\
\left({ }^{* *}\right)\end{array}$ & - & - & $\begin{array}{l}0,79 \\
(* * *)\end{array}$ & 0,16 & - & - \\
\hline
\end{tabular}

Fonte: Cálculos do trabalho.

Nota: $\left({ }^{* *}\right),\left({ }^{* *}\right),\left(^{*}\right)$ indicam significância com $99 \%, 95 \%$ e $90 \%$, respectivamente. Utilizou-se o critério de AIC para a seleçăo das defasagens nas regressōes do teste ADF. KPSS é o teste desenvolvido por Kwiatkowski-Phillips-Schmidt-Shin.

${ }_{28}$ Maiores detalhes sobre os testes de raiz unitária podem ser obtidos em Greene (2002). Além disso, Enders (1995, p. 257), mostra o procedimento usual, em forma esquemática, para testar a estacionariedade das variáveis. testes de raiz unitária para as variáveis da equação $2 .{ }^{28}$ Os resultados estão reportados na Tabela 6 . A conclusão é que as varáveis exportaçóes $(\ln X)$, renda interna $(\ln Y)$ e câmbio real $(\ln \mathrm{C})$ são estacionárias em nível, I(0). Já as variáveis capacidade instalada da indústria nacional $\left(\ln \mathrm{Y}^{\mathrm{P}}\right)$ e renda externa $\left(\ln \mathrm{Y}^{*}\right)$ são estacionárias na primeira diferença, I(1).

Portanto, como as variáveis apresentaram ordem de diferenciação diferente, justifica-se o emprego da abor- dagem de cointegração via modelos autorregressivos de defasagem distribuí$\mathrm{da}$ - ARDL - como proposto por Pesaran et al. (2001), uma vez que esta análise permite identificar a cointegração entre as variáveis, independentemente de suas ordens de integração.

Logo, a partir da equação 3, procurou-se formar as relaçóes de longo prazo entre as variáveis via modelo ARDL. Inicialmente, foi estabelecida a ordem do lag para as variáveis em diferença 
da equação 3. Assim, pelo critério AIC, ${ }^{29}$ a defasagem ótima que não apresentava problema de correlação serial dos resídu$\mathrm{os}^{30}$ no modelo foi lag igual a 1 . Uma vez definida a ordem de defasagem do modelo, o passo seguinte foi verificar a hipótese de relação de longo prazo entre as variáveis em nível da equação 3, através do teste F proposto por Pesaran et al. (op. cit.). No caso, a hipótese nula é: $\mathrm{H}_{0}: \delta_{1}=$ $\delta_{2}=\delta_{3}=\delta_{4}=\delta_{5}=0$, contra a hipótese alternativa $\mathrm{H} 1: \delta_{1} \neq \delta_{2} \neq \delta_{3} \neq \delta_{4} \neq \delta 5 \neq 0$ da equação $3 .^{31}$

$\mathrm{O}$ resultado do teste $\mathrm{F}$ por $\mathrm{MQO}$ apresentou o valor da estatística F calculada igual a 4.272. Dados os valores críticos propostos por Pesaran et al. (op. cit.) para o teste $\mathrm{F}$, pode-se concluir que, com 97,5\% de significância, as variáveis cointegram, já que o valor calculado da es- tatística $\mathrm{F}$ é superior ao valor crítico da banda superior, 4.267..$^{32}$ Logo, há indícios de que as variáveis testadas no modelo cointegram.

Partindo-se do pressuposto de que a hipótese nula do teste $F$ foi rejeitada, procedeu-se a estimação do coeficiente de longo prazo do modelo e a correção de erro associada a esse por meio de modelos ARDL. Com base em um lag máximo de oito defasagens e utilizando os critérios de Akaike e Schwarz, chegou-se ao modelo ARDL (2, 0, 7, 0, 1), com melhor ajuste dos dados, ${ }^{33}$ sendo que o ARDL ( $\left.\mathrm{p}, \mathrm{q}_{1}, \mathrm{q}_{2}, \mathrm{q}_{3}, \mathrm{q}_{4}\right)$ estimado representa, respectivamente, $\ln \mathrm{X}, \ln \mathrm{Y}^{\mathrm{P}}, \ln \mathrm{Y}^{*}, \ln \mathrm{Y}$ e $\ln$ C. Após a identificação do modelo, estimou-se o vetor de coeficientes de longo prazo a ser utilizado no modelo de correçôes de erros. ${ }^{34}$ Assim, o modelo de cor-

\begin{tabular}{|c|c|c|c|}
\hline $\begin{array}{l}{ }^{29} \text { Critério de Informação } \\
\text { de Akaike. }\end{array}$ & $\begin{array}{l}\text { longo prazo entre as variáveis } \\
\text { do modelo. }\end{array}$ & $\begin{array}{l}\text { apresentassem autocorrelação } \\
\text { serial dos resíduos. }\end{array}$ & $\hat{\beta}_{i 0}+\hat{\beta}_{i 1}+\ldots+\hat{\beta}_{i \hat{q}_{i}}$ \\
\hline $\begin{array}{l}30 \text { Pelo teste do Multiplicador } \\
\text { de Lagrange - LM -, } \\
\text { o valor calculado da } \\
\text { estatística qui-quadrado foi } \\
\chi^{2}(12)=14,142 \text { (Prob = 0,29). } \\
\text { Nesse caso, a hipótese nula de } \\
\text { não autocorrelaçáo serial nos } \\
\text { resíduos não pode } \\
\text { ser rejeitada. } \\
\text { 31 Cabe ressaltar que a } \\
\text { hipótese nula do teste é a de } \\
\text { não existência de relação de }\end{array}$ & $\begin{array}{l}32 \text { Para um modelo com } \\
\text { constante, sem tendência e } \\
\text { com k=5. } \\
33 \text { A escolha entre os } \\
\text { melhores modelos } \\
\text { apresentados pelos critérios } \\
\text { de Akaike e Schwarz ocorreu } \\
\text { em funçáo daquele que } \\
\text { apresentasse menor soma } \\
\text { dos quadrados dos resíduos } \\
\text { ou maior coeficiente de } \\
\text { ajustamento - } \mathrm{R}^{2} \text { e náo }\end{array}$ & $\begin{array}{l}{ }^{34} \text { Os coeficientes de longo } \\
\text { prazo de resposta de } \ln \mathrm{X}_{\mathrm{t}} \text { a } \\
\text { uma unidade de mudança nas } \\
\text { variáveis explicativas, } \hat{\theta}_{i} \text {, são } \\
\text { estimados via modelo ARDL } \\
\left(\mathrm{p}, \mathrm{q}_{1}, \mathrm{q}_{2}, \ldots, \mathrm{q}_{\mathrm{k}} \text { ), segundo }\right. \\
\text { Pesaran e Pesaran (2009, } \mathrm{p} \text {. } \\
\text { 463) da seguinte forma: }\end{array}$ & $\begin{array}{l}\qquad 1-\hat{\varphi}_{1}-\hat{\varphi}_{2}-\ldots-\hat{\varphi}_{\hat{p}} \\
\text { com } \mathrm{i}=1,2, \ldots, \mathrm{k} . \text { Onde } \hat{p} \\
\text { e } \hat{q}_{i} \text { são os valores estimados } \\
\text { de p e } \mathrm{q}_{\mathrm{i}}, \text { para } \mathrm{i}=1,2, \ldots, \\
\text { k. Desta forma, o vetor de } \\
\text { correção de erros (ecm) } \\
\text { foi calculado como segue: } \\
\text { ECM }=\ln \mathrm{X}+5,7721 \ln \mathrm{YP} \\
-5,0043 \ln \mathrm{Y}^{*}+4,8797 \ln \mathrm{Y} \\
+1,4047 \ln \mathrm{C}-39,6353 \\
\text { Constante. }\end{array}$ \\
\hline
\end{tabular}


Tabela 7_Estimação do modelo de correções de erro baseado em modelo ARDL $(2,0,7,0,1)$, com "dummy" de degrau e "dummy" para 02/1998

Variável dependente: D(LNX)

Método: Mínimos Quadrados

Amostra (ajustada): 1995M08 2002M12

Observações incluídas: 89 após ajustamento

\begin{tabular}{|c|c|c|c|c|}
\hline & Coeficiente & Erro padrão & Estatística-t & Prob. \\
\hline $\mathrm{D}(\mathrm{LN} X(-1))$ & $-0,215497$ & 0,068955 & $-3,125162$ & 0,0025 \\
\hline $\mathrm{D}\left(\mathrm{LN} \mathrm{Y}^{*}(-4)\right)$ & 15,29177 & 4,562598 & 3,51548 & 0,0012 \\
\hline $\mathrm{D}\left(\mathrm{LN} \mathrm{Y}^{*}(-6)\right)$ & $-17,65235$ & 4,500800 & $-3,922048$ & 0,0002 \\
\hline $\mathrm{D}(\mathrm{LN} \mathrm{C})$ & $-1,409252$ & 0,152575 & $-9,236438$ & 0,0000 \\
\hline $\operatorname{ECM}(-1)$ & $-0,494662$ & 0,085219 & $-5,804618$ & 0,0000 \\
\hline D0298 & $-2,631321$ & 0,452991 & $-5,808775$ & 0,0000 \\
\hline DDP & 0,121462 & 0,069959 & 1,736184 & 0,0863 \\
\hline $\mathrm{R}^{2}$ & 0,708786 & \multicolumn{2}{|c|}{ Máxima verossimilhança } & $-50,35122$ \\
\hline $\mathrm{R}^{2}$ Ajustado & 0,687478 & \multicolumn{2}{|c|}{ Estatística de Durbin-Watson } & 1,975080 \\
\hline Soma dos erros da regressão & 0,443865 & \multicolumn{2}{|c|}{ Critério de Inf. de Akaike } & 1,288792 \\
\hline Soma do quadrado dos resíduos & 16,15529 & \multicolumn{2}{|c|}{ Critério de Schwarz } & 1,484527 \\
\hline
\end{tabular}

Fonte: Elaboração própria.

reçóes de erros baseado em um ARDL (2, $0,7,0,1)$, conforme Tabela 7 , permaneceu com a dummy (DDP) em nível e incorporou a dummy (D0298), referente ao mês de fevereiro de 1998. A inclusão dessa variável mostrou-se significativa e gerou melhora no modelo. Além disso, foram excluídas do modelo as variáveis não significativas, algumas das quais teoricamente influenciariam as exportaçóes, como a renda interna, $Y$, e a capacidade ins- talada, $Y^{P}$. Os preços relativos ou câmbio real, C, e a renda externa, $Y^{*}$, em 4 e 6 defasagens, e a própria variável dependente, exportações de PALQ, X, com uma defasagem, mostraram-se altamente significativas (Tabela 7).

Cabe ressaltar que a variável $\ln \mathrm{C}$ apresentou sinal negativo. Como $C=E(P x / P d)$, o sinal obtido implica que uma elevação da taxa de câmbio em 
Tabela 8_Resumo dos testes de exogeneidade

\begin{tabular}{|c|c|c|}
\hline Testes & Caso 1: Exportações (K) e Câmbio (C) & $\begin{array}{c}\text { Caso 2: } \\
\text { Exportações (X) e Renda interna (Y) }\end{array}$ \\
\hline Probabilidade de X causar C e Y: sentido Granger & $68 \%$ (não causa) & 63\% (não causa) \\
\hline Teste de Engle, Hendry e Richard (1983) & Endógeno & Exógeno \\
\hline 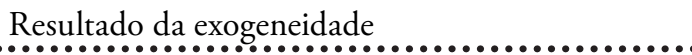 & Fraca & Forte \\
\hline
\end{tabular}

termos reais (desvalorização da moeda brasileira) tem efeito negativo sobre as exportaçóes no curto prazo. Esse resultado pode ser explicado pela possível presença da Curva $\beta^{55}$ nas exportaçóes do setor siderúrgico, em que existe a vigência de contratos pré-fixados para exportação. A dummy que representa os impactos do direito provisório antidumping sobre as exportaçóes de Minas Gerais, DDP, apresentou sinal coerente com a teoria econômica ${ }^{36}$ e foi aceita a um nível de significância de 10\% (Tabela 7).

Como mencionado no trabalho, utilizou-se a hipótese de país pequeno para as exportações de PALQ de MG com destino aos EUA. Segundo Zini (1988), essa hipótese facilitaria a elaboração do modelo, uma vez que pressupóe a exogeneidade estrita de variáveis como câmbio e renda interna. ${ }^{37}$ Entretanto, a questão da exogeneidade de variáveis explicativas pode ser verificada, segundo Bierens (2004), nas abordagens de Engle, Hen- dry e Richard (1983) e de Causalidade de Granger. ${ }^{38}$ Assim, aplicados os procedimentos dos testes de Engle, Hendry e Richard (1983) e de Causalidade de Granger, conclui-se que existe exogeneidade fraca do câmbio em relação às exportaçóes de PALQ e exogeneidade forte da renda interna em relação às exportaçóes de PALQ (Tabela 8). ${ }^{39}$

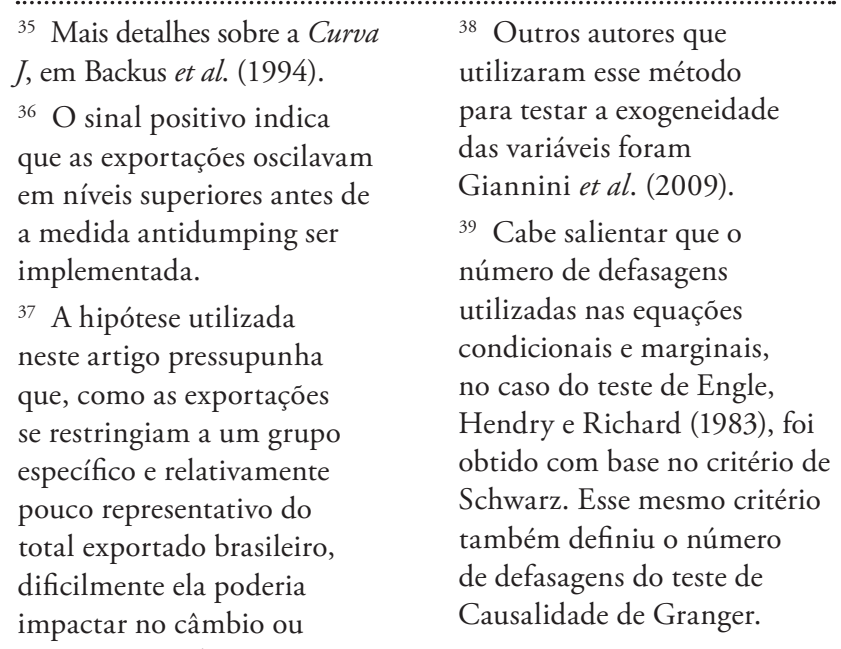


Tabela 9_Estimação do MQ2E com a inclusão do instrumento para câmbio

\section{Variável dependente: DLNK}

Método: Mínimos Quadrados em dois estágios

Amostra (ajustada): 1995M08 2002M12

Variáveis incluídas: 89 após ajustamento

Lista de instrumentos: DLNK DLNK(-1) DLNY2(-4) DLNY2(-6) INSTR ECM(-1) DO298 DDP

\begin{tabular}{|c|c|c|c|c|}
\hline Variável & Coeficiente & Erro padrão & Estatística-t & Prob. \\
\hline $\mathrm{D}(\mathrm{LNX}(-1))$ & -0.212464 & 0.069531 & -3.055653 & 0.0030 \\
\hline $\mathrm{D}\left(\mathrm{LNY}^{*}(-4)\right)$ & 15.29517 & 4.576902 & 3.341816 & 0.0013 \\
\hline $\mathrm{D}\left(\mathrm{LNY}^{*}(-6)\right)$ & -17.63761 & 4.516438 & -3.905204 & 0.0002 \\
\hline $\mathrm{D}(\mathrm{LN} \mathrm{C})$ & -1.395450 & 0.152686 & -9.139326 & 0.0000 \\
\hline $\operatorname{ECM}(-1)$ & -0.499925 & 0.087052 & -5.742846 & 0.0000 \\
\hline D0298 & -2.629370 & 0.454385 & -5.786651 & 0.0000 \\
\hline DDP & 0.122076 & 0.070196 & 1.739064 & 0.0858 \\
\hline $\mathrm{R}^{2}$ & 0.706980 & \multicolumn{2}{|c|}{ Soma do Q. dos resíduos } & 16.25551 \\
\hline $\mathrm{R}^{2}$ ajustado & 0.685539 & \multicolumn{2}{|c|}{ S.D. variável dependente } & 0.793981 \\
\hline Soma dos erros da regressão & 0.445239 & \multicolumn{2}{|c|}{ Estat. de Durbin-Watson } & 1.970568 \\
\hline
\end{tabular}

Fonte: Elaboração própria.

${ }^{40}$ Erro da Equaçáo: $D(\ln P R)=$

$=$ Constante $+D(\ln X)+$ Erro .

Vale ressaltar que o erro desse modelo apresentou pequena correlação negativa com relação às exportações $(-0,02)$ e elevada correlação com o câmbio $(0,88)$.
Como, no caso do câmbio, não foi possível verificar exogeneidade forte em relação às exportaçóes, a estimação realizada na Tabela 7 , utilizando mínimos quadrados ordinários (MQO), pode apresentar resultados inconsistentes e/ou enviesados. Para contornar esse problema, optou-se pela estimação de um modelo de mínimo quadrado em dois estágios (MQ2E), usando um instrumento para corrigir os problemas citados. Buscou-se como instrumento uma variável que estivesse mais correlacionada possí- vel com o câmbio e o mínimo possível com as exportaçóes de PALQ. Para tanto, utilizou-se a parte do câmbio que não era explicada pelas exportaçóes ${ }^{40}$

Os resultados da estimação do MQ2E (Tabela 9) evidenciaram que os sinais ou mesmo a significância estatística de nenhuma das variáveis se alterou em relação ao modelo retratado na Tabela 7 . Portanto, pode-se concluir que, de fato, as variáveis macroeconômicas incorporadas no modelo não alteraram o sentido da dummy DDP. 


\section{2_Incorporação do resultado do modelo econométrico nas matrizes inter-regionais de insumo-produto}

Como sugerido no título desta seção, o objetivo aqui é incorporar auferidos os resultados do modelo econométrico de variação das exportaçóes do Estado de Minas na matriz inter-regional de insumo-produto. Como os coeficientes obtidos nas Tabelas 7 e 9, a partir da inclusáo das variáveis de controle macroeconômicas, estão expressos em logaritmo natural e primeira diferença, o resultado da dummy (DDP) não expressa a taxa de redução da mesma. Portanto, optou-se por utilizar o resultado da Tabela 4 . O coeficiente da dummy de direito provisório, neste caso, foi 0.646811. Para extrair a taxa de diminuição das exportaçóes em Minas Gerais, utilizou-se o procedimento de Halversen e Palmquist (1980), ou seja, o antilog na base $e$ menos um.

$\mathrm{O}$ resultado indica que as exportaçôes diminuíram aproximadamente 0,91\% ao mês após a implementação do direito provisório. Considerando os quatro anos em análise neste trabalho (1999 a 2002), pode-se concluir que o decréscimo médio das exportaçóes de produtos de aço laminados a quente foi de aproximadamente $54,47 \%$. Isso significa uma diminuição anual das exportaçôes da ordem de, aproximadamente, 11,48\%.
Para agregar esse resultado nas matrizes inter-regionais de insumo-produto, faz-se necessário incorporá-lo no total exportado pelo setor siderúrgico de Minas Gerais. Na Tabela 10, observa-se que as exportaçóes de produtos siderúrgicos provenientes de Minas Gerais e destinadas aos Estados Unidos são responsáveis, em média, por $30,15 \%$ do total exportado pela siderurgia do Estado. Quando consideradas, porém, as exportaçóes dos produtos de aço laminados a quente (PALQ), essa participação média diminui para $2,13 \%$ do total exportado pelo setor em MG.

Como referido anteriormente, a medida provisória adotada contra as exportações de Minas Gerais foi implementada em fevereiro de 1999. Nesta simulação, foram considerados os quatro anos seguintes à adoção dessa medida, incluindo o próprio ano de 1999. O resultado do modelo econométrico foi distribuído equitativamente para os referidos anos. As exportações diminuíram aproximadamente $0,91 \%$ ao mês, acumulando um total de $54,47 \%$ entre 1999 e 2002, ou 11,48\% a cada ano. Logo, o percentual verificado da participação dos PALQs no total exportado seria acrescido de 11,48\%. Esses resultados estáo expostos na Tabela 11. 
Tabela 10_Participação dos produtos de aço laminados a quente (PALQ) no total exportado pelo setor siderúrgico de Minas Gerais

\begin{tabular}{|c|c|c|c|c|c|}
\hline Período & $\begin{array}{l}\text { Exportações totais } \\
\text { da siderurgia de MG }\end{array}$ & $\begin{array}{c}\text { Exportações da } \\
\text { siderurgia de MG } \\
\text { para os EUA }\end{array}$ & $\begin{array}{c}\text { Participação } \\
\text { da siderurgia } \\
\text { (MG } \rightarrow \text { EUA) no total }\end{array}$ & $\begin{array}{c}\text { Exportações } \\
\text { dos PALQs de MG } \\
\text { para os EUA }\end{array}$ & $\begin{array}{l}\text { Participação dos PALQs } \\
\text { (MG } \rightarrow \text { EUA) no total }\end{array}$ \\
\hline & Bilhões US\$ & Bilhões US\$ & $\%$ & Bilhões US\$ & $\%$ \\
\hline 1999 & 1.264 & 0.380 & 30,04 & 0.034 & 2,72 \\
\hline 2000 & 1.523 & 0.507 & 33,32 & 0.035 & 2,30 \\
\hline 2001 & 1.272 & 0.372 & 29,26 & 0.021 & 1,67 \\
\hline 2002 & 1.493 & 0.418 & 28,00 & 0.028 & 1,84 \\
\hline Média & 1.388 & 0.419 & 30,15 & 0.030 & 2,13 \\
\hline
\end{tabular}

Fonte: Brasil/MDIC/ALICEweb (2008).

A Tabela 11 revela os efeitos da medida antidumping, implementada em fevereiro de 1999, sobre as exportaçóes dos PALQs do setor siderúrgico de Minas Gerais. Assim, para o ano de 1999, por exemplo, a participaçáo desses produtos no total exportado pela siderurgia de Minas Gerais seria de 3,032\%, no caso de não ocorrência da aplicação do direito antidumping por parte dos EUA. Percebe-se que a participação dos PALQs no total exportado pelo setor não é muito expressiva. No entanto, mesmo um impacto pequeno sobre as exportaçóes pode alterar a produçáo e o emprego do setor siderúrgico de Minas Gerais e gerar

Tabela 11_Impactos percentuais da medida "antidumping" sobre as exportações totais do setor siderúrgico de Minas Gerais, entre 1999 e 2002

Participação dos PALQs no total exportado pela siderurgia de MG (\%)

\begin{tabular}{|c|c|c|c|c|}
\hline Período & 1999 & 2000 & 2001 & 2002 \\
\hline Valores reais & 2,72 & 2,3 & 1,67 & 1,84 \\
\hline Valor estimado & 3,032 & 2,564 & 1,862 & 2,051 \\
\hline
\end{tabular}

Fonte: Cálculos do trabalho. 
efeitos induzidos sobre os demais setores, dentro e fora do Estado. Além disso, a análise setorial dos efeitos possibilita obter resultados sobre quais setores seriam mais afetados se as exportaçóes da siderurgia de Minas Gerais sofressem maiores embargos.

\subsection{1_Impactos setoriais sobre a produção e o emprego}

$\mathrm{Na}$ Tabela 12, percebe-se que, em 1999, as exportaçóes do setor siderúrgico passaram de, aproximadamente, R\$ 2,014 bilhōes para $\mathrm{R} \$ 2,020$ bilhóes, caso a medida antidumping náo tivesse sido adotada. Ou seja, um incremento de pouco mais de R 6 milhóes nas exportaçóes. A maior variação ocorreu em 2002, quando as exportaçóes aumentaram em quase R 9 milhóes. Isso se deu em razão de as exportações reais nesse ano terem alcançado valor superior aos demais. ${ }^{41}$ Os valores estimados para as demandas finais (ver Tabela 12) foram utilizados nas matrizes de insumo-produto em seus respectivos anos, o que possibilitou obter resultados sobre o impacto dessas variaçóes nas exportaçóes sobre a produção e o emprego, nos setores de Minas Gerais e no restante do Brasil.

Com relação aos impactos sobre a produção dos setores, pode-se notar que as variaçóes ocorrem somente na esfera dos milhóes. Logo, conclui-se que os impactos, em termos percentuais, sobre a produção dos setores de Minas Gerais e do restante do Brasil, são relativamente pequenos. $\mathrm{O}$ que se deve, principalmente, a pouca representatividade dos PALQs (alvo da medida antidumping por parte dos EUA) nas exportaçóes totais do setor siderúrgico de Minas Gerais (em média 2,13\%, conforme a Tabela 10) e também pode estar relacionado com a elevação da taxa de câmbio (R\$ / US\$) verificada no início de 1999.

Uma vez que o impacto da medida restritiva adotada contra as exportações da siderurgia de Minas Gerais, em termos de produçấo total dos setores, foi ínfimo, tanto dentro do Estado quanto fora dele, cabe a seguinte questão: como reagiriam os setores, de Minas Gerais e do restante do Brasil, caso as exportações da siderurgia mineira sofressem novas restriçōes?

Para responder a essa questão, dividiu-se o coeficiente de variação em cada setor pela variação total (Minas Gerais + Restante do Brasil) e multiplicou-se o resultado por 100. Esse procedimento forneceu a participação percentual, sobre a produção total de cada setor, no impacto verificado. Os resultados estão dispostos na Tabela 13.

Retirando-se o setor de ferro e aço de Minas Gerais (MG) da Tabela 13, e
${ }^{41}$ Cabe ressaltar que o "valor real" adotado neste trabalho é, na realidade, o valor obtido nas matrizes atualizadas por Souza (2008). 
Tabela 12_Valores estimados das exportações e demanda final da siderurgia de Minas Gerais, para os anos de 1999 a 2002, caso não houvesse sido adotada uma medida "antidumping" (valores correntes)

\begin{tabular}{|c|c|c|c|c|c|}
\hline & & 1999 & 2000 & 2001 & 2002 \\
\hline & Consumo intermediário & 7.150 .397 & 9.152 .130 & 9.782 .057 & 9.741 .783 \\
\hline & $\mathrm{C}+\mathrm{I}+\mathrm{G}$ & 2.583 .463 & 2.916 .486 & 3.129 .336 & 3.432 .304 \\
\hline \multirow{2}{*}{ Exportaçóes } & Valores reais & 2.014 .325 & 2.430 .386 & 2.728 .948 & 4.370 .341 \\
\hline & Valor estimado & 2.020 .569 & 2.436 .705 & 2.734 .133 & 4.379 .519 \\
\hline \multirow{2}{*}{ Demanda final } & Valores reais & 4.597 .788 & 5.346 .872 & 5.858 .285 & 7.802 .645 \\
\hline & Valor estimado & 4.604 .032 & 5.353 .191 & 5.863 .470 & 7.811 .823 \\
\hline
\end{tabular}

Fonte: Cálculos do trabalho.

Notas:

1. As exportaçôes reais para 1999 a 2000 foram multiplicadas pelos valores estimados da Tabela 9, menos a participaçăo real dos PALQs para os seus respectivos anos, mais um;

2. $\mathrm{C}+\mathrm{I}+\mathrm{G}$ refere-se a consumo, investimento e gastos do governo;

3. A demanda final é o somatório de $\mathrm{C}+\mathrm{I}+\mathrm{G}+$ exportaçóes.

calculando-se uma média entre os anos de 1999 a 2002, podem-se perceber quais setores, em MG e Restante do Brasil (RB), que concentraram os efeitos da medida antidumping impostas à siderurgia de MG. Nota-se que o setor que mais perderia, em termos de produção, seria o setor de ferro e aço do RB, em que aproximadamente $5 \%$ do efeito total ficou concentrado. Isso indica que, apesar de estarem em regióes diferentes, existe forte ligação entre a produção siderúrgica em MG e no RB.
O setor de transporte em MG também se mostrou sensível a variaçoóes na demanda final da siderurgia de MG. Isso se deve ao fato de que diversos produtos oriundos desse setor utilizam produtos siderúrgicos em seu processo de produção. Além desse, outros setores em MG também se mostraram sensíveis a variações de produção no setor de ferro e aço. Os principais foram: metais não ferrosos e outras metalurgias, extrativa mineral, minerais não metálicos e agropecuária (Gráfico 1). 
Tabela 13_Distribuição do impacto, sobre a produção, pelos setores de Minas Gerais e do restante do Brasil (valores percentuais)

\begin{tabular}{|c|c|c|c|c|c|}
\hline & Setores & 1999 & 2000 & 2001 & 2002 \\
\hline \multirow{13}{*}{ 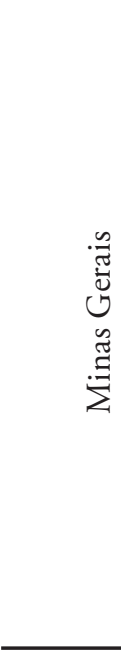 } & Agropecuária & 1,70 & 1,58 & 1,55 & 1,93 \\
\hline & Extrativa mineral & 2,64 & 4,49 & 1,65 & 0,36 \\
\hline & Minerais não metálicos & 1,87 & 2,03 & 2,06 & 2,17 \\
\hline & Ferro e aço & 78,25 & 75,68 & 77,73 & 77,66 \\
\hline & Metais não ferrosos e outras metalurgias & 2,52 & 2,64 & 2,69 & 2,77 \\
\hline & Papel e celulose & 0,09 & 0,10 & 0,11 & 0,12 \\
\hline & Química & 0,64 & 0,66 & 0,70 & 0,76 \\
\hline & Alimentos e bebidas & 0,14 & 0,16 & 0,15 & 0,17 \\
\hline & Têxtil e vestuário & 0,13 & 0,14 & 0,15 & 0,17 \\
\hline & Outras indústrias & 1,03 & 1,22 & 1,24 & 1,35 \\
\hline & Comércio e serviços & 0,60 & 0,57 & 0,66 & 0,70 \\
\hline & Transporte & 3,06 & 3,17 & 3,25 & 3,38 \\
\hline & Serviços públicos & 0,03 & 0,21 & 0,26 & 0,34 \\
\hline \multicolumn{2}{|c|}{ Participação dos setores de Minas Gerais } & 92,71 & 92,65 & 92,20 & 91,87 \\
\hline \multirow{13}{*}{ 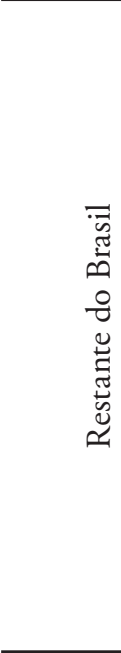 } & Agropecuária & 0,22 & 0,21 & 0,23 & 0,28 \\
\hline & Extrativa mineral & 0,79 & 0,88 & 0,91 & 1,02 \\
\hline & Minerais não metálicos & 0,17 & 0,18 & 0,19 & 0,21 \\
\hline & Ferro e aço & 4,86 & 4,78 & 5,07 & 5,09 \\
\hline & Metais não ferrosos e outras metalurgias & 0,46 & 0,47 & 0,50 & 0,53 \\
\hline & Papel e celulose & 0,10 & 0,10 & 0,11 & 0,13 \\
\hline & Química & 0,24 & 0,24 & 0,26 & 0,28 \\
\hline & Alimentos e bebidas & 0,01 & 0,02 & 0,01 & 0,02 \\
\hline & Têxtil e vestuário & 0,04 & 0,05 & 0,05 & 0,06 \\
\hline & Outras indústrias & 0,06 & 0,07 & 0,08 & 0,09 \\
\hline & Comércio e serviços & 0,04 & 0,04 & 0,04 & 0,05 \\
\hline & Transporte & 0,28 & 0,29 & 0,32 & 0,35 \\
\hline & Serviços públicos & 0,03 & 0,03 & 0,03 & 0,04 \\
\hline \multicolumn{2}{|c|}{ Participaçáo dos setores do restante do Brasil } & 7,29 & 7,35 & 7,80 & 8,13 \\
\hline \multicolumn{2}{|l|}{ Total } & 100 & 100 & 100 & 100 \\
\hline
\end{tabular}

Fonte: Elaboraçăo própria do autor. 


\section{Gráfico 1_Impacto da medida "antidumping" imposta à siderurgia de MG, através dos PALQs, sobre a produção dos demais setores de MG e RB - excluindo-se o setor de ferro e aço de MG (valores percentuais)}

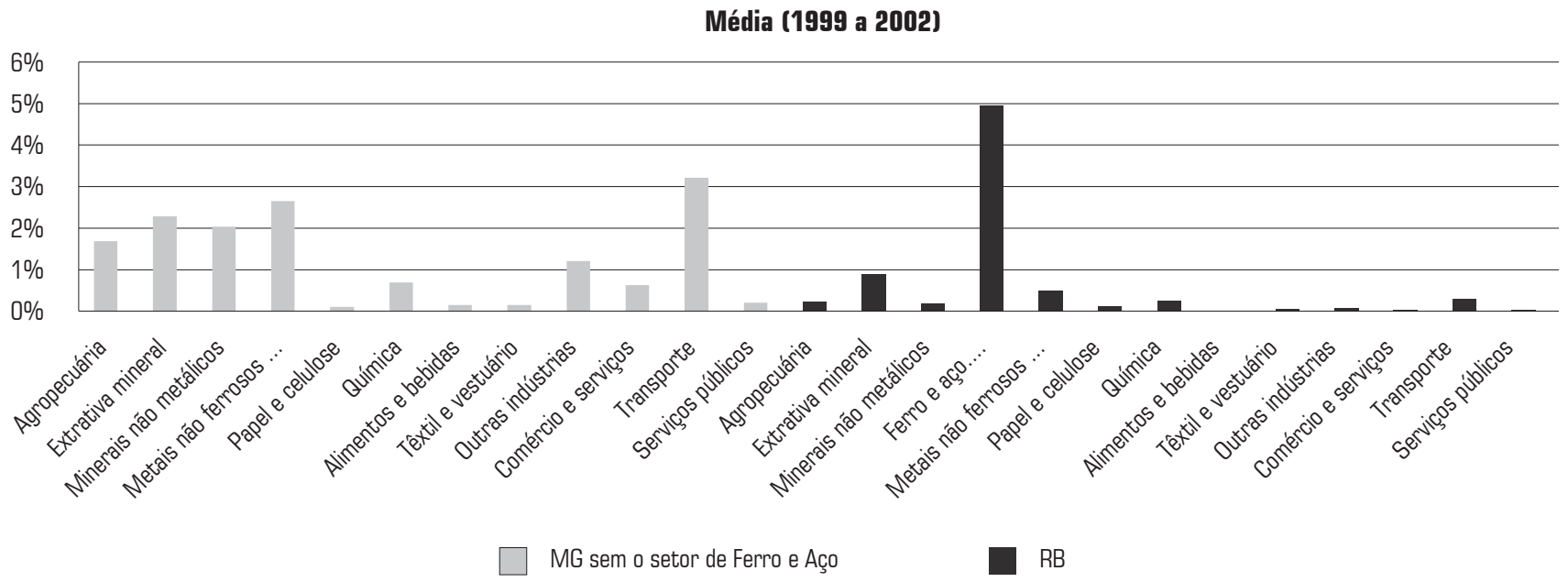

Fonte: Elaboração própria.

42 Para obter o impacto dessa medida antidumping sobre o número de empregados, por setor, em Minas Gerais e no Restante do Brasil, para os anos de 1999 a 2002, utilizouse o vetor real de conversão de emprego (E) e os valores estimados da demanda total (DT) para cada ano (equaçôes 6 e 7).
Para a análise do número de empregos que seriam criados em cada setor, caso a medida antidumping não tivesse ocorrido, foram utilizados os valores estimados para a produção setorial. ${ }^{42}$ Assim, constatou-se que, em todos os anos analisados, o maior impacto ocorreu em Minas Gerais. Considerando o ano de 1999, conclui-se que a retração das exportaçóes de produtos de aço laminados a quente, provenientes de Minas Gerais e decorrentes da medida antidumping adotada pelos EUA, inibiu a criação de
117 novos postos de trabalho no Brasil, sendo 83 deles no Estado e 34 no restante do Brasil (valores que correspondem a $70,94 \%$ e $29,06 \%$ do total). No ano de 2002 , foram verificadas as maiores perdas, ou seja, de 136 vagas. $\mathrm{O}$ menor resultado foi obtido em 2001, em que foram criados apenas 82 postos.

As maiores perdas ocorreram justamente no setor siderúrgico. Em todos os anos analisados, o número de empregos que seria criado na siderurgia de Minas Gerais oscilou em torno de 51,95\% 
Gráfico 2_Número de empregos que seriam criados caso a medida "antidumping" imposta à siderurgia de MG não tivesse ocorrido excluindo-se o setor de ferro e aço de MG (valores percentuais)

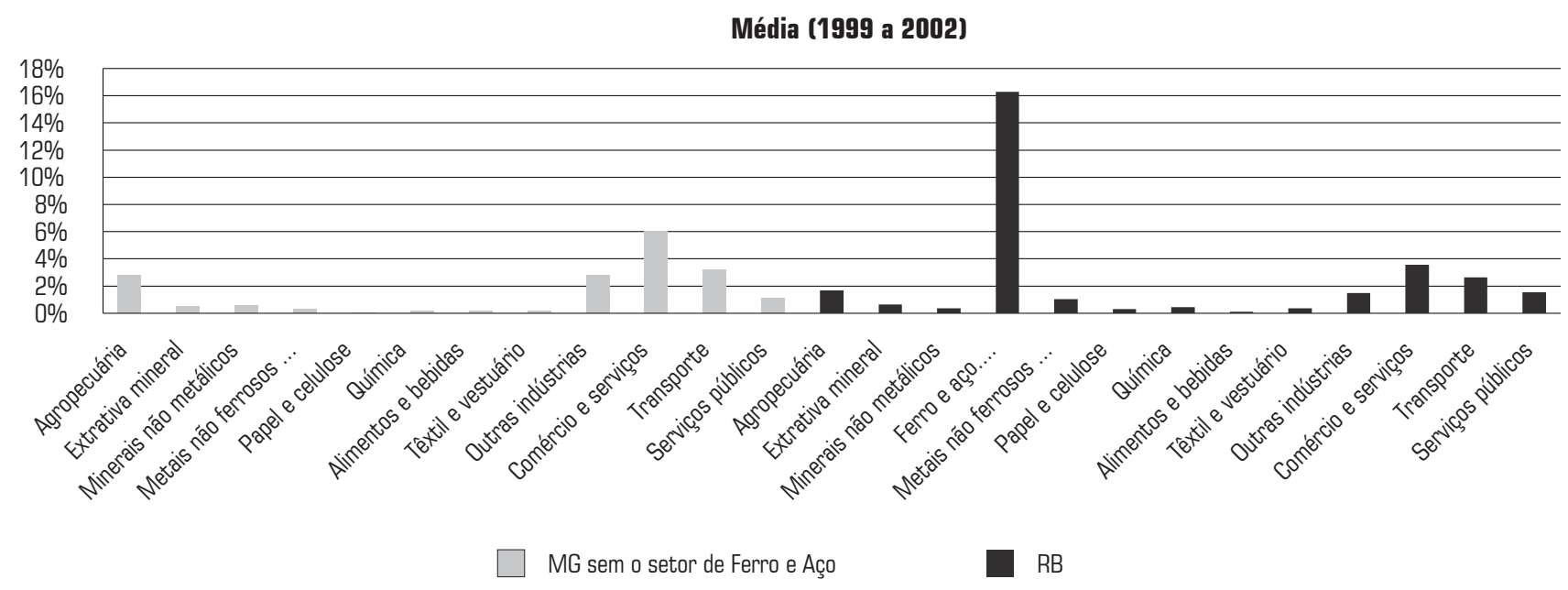

Fonte: Elaboração própria.

do total verificado no país. Os resultados para os demais setores de MG e restante do Brasil estão reportados no Gráfico 2. No caso da siderurgia do restante do país, esse valor ficou em torno de 16,29\%, entre 1999 e 2002 (média dos quatro anos). Logo, percebe-se que existe relação direta entre a produção siderúrgica de Minas Gerais e o número de empregos gerados nesse setor, no restante do Brasil. O setor de comércio e serviços de Minas Gerais também seria afetado. Em média, 6,01\% das vagas de trabalho que seriam criadas no Brasil seriam destinadas a esse setor do Estado. O mesmo setor, no restante do Brasil, seria responsável por, aproximadamente, $3,57 \%$ das vagas criadas no período analisado.

O setor de transportes, tanto dentro do Estado quanto no restante do país, também apresentou valores médios relativamente importantes, $3,17 \%$ e $2,62 \%$, respectivamente. $\mathrm{O}$ setor agropecuário aparece em seguida, com 2,79\% em Minas Gerais (mesmo valor que o setor de outras indústrias no Estado) e 1,69\% no 


\footnotetext{
«3 agropecuário podem estar subdimensionados, já que a RAIS leva em consideração apenas os trabalhadores com carteira assinada.
}

restante do Brasil. ${ }^{43}$ Alguns setores como papel e celulose, alimentos e bebidas, serviços públicos, extrativa mineral, metais não ferrosos e outras metalurgias e química revelaram impactos no restante do Brasil superiores aos verificados em Minas Gerais. Isso pode ser um indício de que a siderurgia em Minas Gerais se relaciona mais com esses setores fora do Estado do que dentro deste (Gráfico 2).

\section{6_Conclusão}

$\mathrm{O}$ intuito deste trabalho foi analisar o impacto de medidas antidumping (AD) aplicadas pelos Estados Unidos sobre as exportaçóes do setor siderúrgico de Minas Gerais, mais especificamente produtos de aço laminados a quente (PALQ) para o período entre 1999 a 2002. Os resultados mostraram que tal medida teve efeitos estatisticamente significativos sobre a redução no fluxo de comércio. Além disso, verificou-se que o aumento de custo dos PALQs, gerado pela medida $\mathrm{AD}$, não levou a um "efeito substituição" sobre os produtos de aços laminados a frio (PALF). Logo, não houve indícios de que a economia americana passou a comprar mais PALFs em detrimento dos PALQs.

Expandindo a análise com a incorporação de variáveis macroeconômicas de controle, como câmbio, renda inter- na e externa, preço dos produtos exportados, preço dos produtos domésticos e capacidade instalada de indústria nacional, observou-se que a inclusão dessas não alterou o sentido do impacto da medida antidumping sobre as exportaçóes de $\mathrm{Mi}$ nas Gerais. Entretanto, os resultados evidenciaram que outras variáveis, além da medida antidumping, poderiam estar influenciando as exportaçóes de PALQ de Minas Gerais. Cabe ressaltar que resultados muito semelhantes foram obtidos quando se buscou contornar o problema da possível endogeneidade da variável "câmbio". Obtiveram-se os mesmos nível de significância estatística e sinais das variáveis do modelo original.

Com relação à análise da integração dos resultados econométricos com a abordagem de insumo-produto, foi possível obter o resultado dessa medida sobre o produto e emprego de cada setor de Minas Gerais e do restante do Brasil. No que diz respeito à produção dos setores, pode-se concluir que o setor mais afetado seria realmente a siderurgia em Minas Gerais, no qual o impacto representou sempre mais de $75 \%$ do total, entre 1999 e 2002. O segundo setor mais afetado, embora apresente efeito significativamente inferior ao setor de ferro e aço de Minas Gerais, seria a siderurgia do restante do Brasil, em que o efei- 
to oscilou em torno de $5 \%$ em todos os anos analisados.

Isso mostra que existe inter-relação entre a produção dos setores siderúrgicos de Minas Gerais e do restante do Brasil. Outros setores em Minas Gerais também incorporaram parte do efeito sobre a produção, estando entre eles os de transporte, metais não ferrosos e outras metalurgias, extrativa mineral e outras metalurgias e outras indústrias, que variaram entre $1 \%$ e $4,5 \%$, entre 1999 e 2002. Juntos, os setores de Minas Gerais incorporaram algo em torno de $92 \%$ do impacto total verificado na produção. Logo, a regiáo mineira seria a principal prejudicada, em termos de produção, caso as exportações do setor siderúrgico do Estado sofressem embargos.

Com relação ao emprego, pode-se destacar o impacto gerado pela diminuição das exportações sobre o próprio setor siderúrgico em Minas Gerais. Mais da metade dos postos de trabalho que seriam criados, caso nenhuma medida antidumping tivesse sido adotada, seriam destinados à siderurgia deste Estado. $\mathrm{O}$ setor siderúrgico do restante do país ficaria com mais de $16 \%$ das vagas. Tal resultado fornece indícios de que a siderurgia mineira apresenta forte ligação com o mesmo setor no restante do Brasil.
Além desse, pode-se destacar o efeito sobre o setor de comércio e serviços, tanto dentro como fora de Minas Gerais. Os resultados mostraram que esse setor apresentou boa sensibilidade a variações nas exportações da siderurgia mineira no que se refere a emprego. Logo, se as exportaçóes de ferro e aço diminuírem, pode-se esperar que muitas vagas de trabalho sejam perdidas no comércio e serviços, em ambas as regióes. Alguns setores apresentaram valores maiores no restante do Brasil do que em Minas Gerais. Talvez a siderurgia em Minas Gerais tenha mais relaçóes comerciais com esses setores fora do Estado.

Como observado, o impacto dessa medida antidumping sobre as exportaçôes da siderurgia de Minas Gerais foi relativamente pequeno. Isso pode ser atribuído, principalmente à pequena participação dos PALQs (alvos de medidas $\mathrm{AD}$ ) sobre as exportações da siderurgia de Minas Gerais. Além disso, pode-se citar o efeito do câmbio flutuante, adotado no princípio de 1999, que gerou desvalorização da moeda nacional e o incentivo às exportaçóes, o que possivelmente afetou os resultados obtidos neste trabalho.

Logo, os efeitos desencadeados sobre a produção e emprego dos demais setores em Minas Gerais e no restante do 
Brasil também foram pouco expressivos. Uma alternativa seria incluir mais parceiros comerciais, e não somente os EUA, que também tivessem recorrido a medidas antidumping contra o setor. Outra possibilidade seria inserir uma quantidade maior de produtos oriundos da siderurgia que também foram alvo de medidas. No entanto, esta análise permitiu que alguns setores pudessem ser apontados como aqueles que mais seriam afetados caso uma medida restritiva onerasse as exportaçóes do setor siderúrgico de Minas Gerais de forma mais contundente. Entre esses, pode-se citar a própria siderurgia, de Minas Gerais e do restante do Brasil, no que diz respeito à produção e ao emprego.

Cabe ressaltar que este trabalho não encerra o tema sobre medidas protecionistas e comércio internacional. Existem várias perspectivas e melhoramentos que podem ser efetuados levando-se em consideração o que foi tratado aqui. Como exemplo, podem-se citar alternativas de pesquisa que incluam maior número de produtos siderúrgicos alvo de medidas $\mathrm{AD}$; que incorporem o efeito de outras medidas de defesa comercial, como as medidas compensatórias e salvaguardas, e que verifiquem a possibilidade de desvio de comércio quando o país não é citado. 


\section{Referências bibliográficas}

\author{
ARAÚJO Jr., J. T.; MACARIO, \\ C.; STEINFATT, $\mathrm{K}$. \\ Antidumping in the Americas. \\ CEPAL-SERIE Comércio \\ internacional, $\mathrm{n}^{0} 12,2001$.
}

BACKUS, D. K.; KEHOE, P. J.; KYDLAND, F. E. Dynamics of the trade balance and the terms of trade: the J-Curve. American Economic Review, v. 84, n. 1, p. 84-103, 1994.

BANERJEE, A.; DOLADO, J.; MESTRE, R. Error-correction mechanism test for cointegration in single-equation framework. Journal of Time Series Analysis, v. 19, p. 267-283, 1998.

BDMG - Banco de Desenvolvimento de Minas Gerais e FIPE - Fundação Instituto de Pesquisas Econômicas (BDMG e FIPE/ USP). Matriz inter-regional de insumo produto para Minas Gerais/resto do Brasil. Belo Horizonte. 2002.

BEAUMONT, P. M. Supply and demand interaction: Integrated econometric and input-output models. International Regional Science Review, v. 13, p. 167-181, 1990.
BIERENS, H. J. Var models with exogenous variable. Fevereiro 2004. Disponível_em: <http:// econ.la.psu.edu/-hbierens/ EasyRegTours/VAR_Tourfiles/ VARX.PDF>. Acesso em: jan. 2011.

BLONIGEN, B.; PRUSA, T. Antidumping. NBER Working Paper, no. 8398, 2001.

BRAGA, H. C.; MARKWALD,

R. C. Funçóes de oferta e demanda das exportaçóes de manufaturados no Brasil: Estimação de um modelo simultâneo. Pesquisa e

Planejamento Econômico, v.13, n.3, p. 707-744, dez. 1983.

BRASIL. Ministério do

Desenvolvimento, Indústria e Comércio Exterior (MDIC). Secretaria de Comércio Exterior (SECEX). ALICEweb, Sistema de Análise das Informaçôes de Comércio Exterior. Disponível em: $<$ http://aliceweb.desenvolvimento. gov.br>. Acesso em: 20 de Agosto de 2008 .
BRASIL. Ministério do Desenvolvimento, Indústria e Comércio Exterior (MDIC). Departamento de Defesa Comercial (DECOM). Órgão da Secretaria de Comércio Exterior (SECEX). Relatório DECOM 2006. Disponível em:<http:// www.desenvolvimento.gov.br>. Acesso em: 20 de Julho de 2008.

BRASIL. Ministério do Desenvolvimento, Indústria e Comércio Exterior (MDIC). Nomenclatura Comum do Mercosul (NCM). Disponível em: $<$ http://www.desenvolvimento. gov.br/sitio/interna/interna. php?area $=5 \&$ menu $=1090>$. Acesso em: 15 de Janeiro de 2009.

BRASIL. Ministério do Trabalho e Emprego (MTE). Relação Anual de Informaçóes Sociais (RAIS). Brasília, 2009. Disponível em: $<$ http://www.mte.gov.br/rais/ default.asp $>$. Acesso em: 05 de Fevereiro de 2009.

\section{CARVALHO, A.; DE NEGRI,}

J. A. Estimação de equaçôes de importação e exportação de produtos agropecuários para o Brasil (1977/1998). Brasília: IPEA, Texto para Discussão, n. 698. 2000.
COSTA, C. C. da; BURNQUIST, H. L. Medidas protecionistas utilizadas pelos Estados Unidos e União Europeia para o açúcar: Impacto sobre a economia das regióes exportadoras do Brasil. 2004. $291 \mathrm{f}$. Tese (Doutorado em Economia Aplicada) - ESALQ, Universidade de São Paulo, São Paulo, 2004.

ENDERS, W. Applied Econometric Time Series. John Willey \& Sons, Inc. 1995.

ENGLE, R. F.; HENDRY,

D. F.; RICHARD, J. F.

Exogeneity. Econometrica, v. 51, p. 277-304, 1983.

FIRME, V. A. C. Impactos de medidas antidumping adotadas pelos EUA sobre o setor siderúrgico e suas consequências para a economia de Minas Gerais e o restante do Brasil. 2009.

115f. Dissertação (Mestrado em Economia Aplicada) - Faculdade de Economia e Administração, Universidade Federal de Juiz de Fora, Juiz de Fora, 2009.

GARDNER, B. L. The economics of agricultural policies. New York: Macmillan Publishing Company, 1987. p. 387. 
GIANNINI, F. A.; DIAS, M. H. A.; DIAS, J. Ciclos de negócios: Um estudo empírico para as flutuaçôes da economia brasileira entre 1992 e 2007. ENCONTRO DA ANPEC, 37., 2009,

Foz do Iguaçu. Anais... Foz do Iguaçu, 2009.

GOLDSTEIN, M. e KHAN, M. The Supply and Demand for Exports: A Simultaneous Approach. Review of Economics and Statistics, 60, 275-286. 1978.

GREENE, W. H. Econometric Analysis. 5. ed. New Jersey:

Prentice Hall, 2002.

GUILHOTO, J. J. M. Análise de insumo-produto: Teoria $\mathrm{e}$ fundamentos. Apostila FEA/USP. São Paulo, 2004

GUILHOTO, J.J.M., U.A. SESSO Filho. Estimação da Matriz Insumo-Produto a Partir de Dados Preliminares das Contas Nacionais. Economia Aplicada. Vol. 9. N. 2. pp. 277-299, AbrilJunho 2005.

HADDAD, E. A.; DOMINGUES, E. P. Matriz inter-regional de insumoproduto São Paulo/Resto do Brasil. NEREUS - Núcleo de Economia Regional e Urbana da Universidade de São Paulo, Texto para Discussão: 10-2003, 2003.

HALVERSEN, R.; PALMQUIST, R. The interpretation of dummy variables in semilogarithmic equations. American Economic Review, v. 70, n. 3 , p. 474-475, 1980.
IBGE - Instituto Brasileiro de Geografia e Estatística. Disponível em: http://www. ibge.gov.br/. Acesso em 20 de Novembro de 2007.

IPEADATA - Dados do Instituto de Pesquisa Econômica Aplicada. Disponível em: <http://www. ipeadata.gov.br>. Acesso em: 15 de Setembro de 2008.

ISARD, W.; AZIZ, I. J.; DRENNAN, M. P.; MILLER,

R. E.; SALTZMAN, S.; THORBECK, E. Methods of Interregional and Regional Analysis. New York: Ashgate, 1998.

KONING, J.;

VANDENBUSSCHE, $\mathrm{H}$.; SPRINGAEL, L. Import diversion under European antidumpingpolicy. NBER Working Paper n. 7340. 1999.

MILLER, R. E.; BLAIR,

P. D. Input-output analysis:

Foundations and extensions. $2^{\text {nd }}$ edition. Cambridge: Cambridge University Press, 2009.

MIRANDA, P. Aplicação do direito antidumping e o impacto sobre as exportações brasileiras. Documento IPEA/CEPAL, 2003.

PATRIOTA, A. de A. Barreiras a produtos brasileiros no mercado dos Estados Unidos. Relatório da Fundação Centro de Estudos do Comércio Exterior (FUNCEX), 2007.
PEROBELLI, F. S.; FARIA, W. R.; GUILHOTO, J. J.

M. Impacto das exportaçóes brasileiras para o Mercosul, União Européia e Nafta sobre a produção e emprego: Uma análise de insumo-produto para 19972001. In: CONGRESSO DA SOCIEDADE BRASILEIRA DE ECONOMIA E SOCIOLOGIA RURAL, 44., 2006, Fortaleza. Anais..., 2006, Fortaleza.

PESARAN, M. H.; SHIN, Y.; SMITH, R. J. Bounds testing approaches to the analysis of level relationships. Journal of Applied Econometrics, v. 16, p. 289-326, 2001.

PESARAN, B.; PESARAN, M.

H. Times series econometrics:

Using Microfit 5.0. Oxford:

Oxford University Press, 2009.

PORSSE, A. A.; HADDAD, E. A.; RIBEIRO, E. P. Estimando uma matriz de insumo-produto inter-regional Rio Grande do Sul - Restante do Brasil. NEREUS Núcleo de Economia Regional e Urbana da Universidade de São Paulo, Texto para Discussāo: 20 2003, 2003

PORTUGAL, M. S. Brazilian foreign trade: Fixed and time varying parameter models.

Doctor of Philosophy Thesis, University of Warwick,

Department of Economics, 1992.

PRUSA, T. The trade effects of U.S. antidumping actions. NBER Working Paper n. 5.440.1996.
PRUSA, T. J. On the spread and impact of antidumping. NBER Working Paper, 7.404. 1999.

REY, S. J. The performance of alternative integration strategies for combining regional econometric and input-output models inter-regional.

Regional Science Review, v. 21, n. 1, p. 1-36, 1998.

REY, S. J. Integrated regional econometric and input-output modeling. Discussion Paper. San Diego University, 1999.

REY, S. J. Integrated regional econometric + input-output modeling: Issues and opportunities. Regional Science, 2000.

SOUZA, R. M. Exportaçōes e consumo de energia elétrica: Uma análise baseada na integração de modelos econométrico e de insumo-produto interregional para Minas Gerais e o restante do Brasil. 2008. 114 f. Dissertação (Mestrado em Economia Aplicada) - Faculdade de Economia a Administração, Universidade Federal de Juiz de For a, Juiz de Fora, 2008.

STAIGER, R.; WOLAK, F. Measuring industry-specific protection: Antidumping in the United States. Brookings papers on Economic Activity, Microeconomics, 1994. 
TAYLOR, C. T. The economic effects of withdrawn antidumping investigations: Is there evidence of collusive settlements? Journal of International Economics, v. 62, 2004 .

VASCONCELOS, C. R. F.; VASCONCELOS, S. P.

Medidas "antidumping" e resultados colusivos: $\mathrm{O}$ caso do PEBDL na economia brasileira. Nova Economia, v. 15, n. 3, p. 117-141, 2005.

WILLIG, R. D. Economic effects of antidumping policy. In: LAWRENCE, R. Z. (Ed.). Brookings Trade Forum 1998. Washington: Brookings Institution Press, 1998.

ZANARDI, M. Anti-dumping: What are the numbers to discuss at Doha? The Word Economy, v. 27, n. 3, p. 403-433, 2004.

ZINI, A. A. Funçôes de exportação e importação para o Brasil. Pesquisa e Planejamento Econômico, v. 19, n. 3, p. 615-662, dez. 1988.

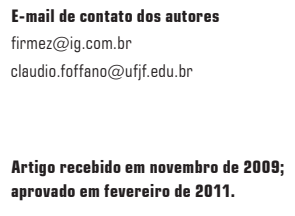

